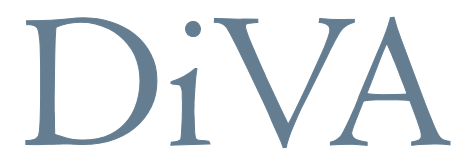

http://uu.diva-portal.org

This is an author produced version of a paper published in Natural Resources Research. This paper has been peer-reviewed but does not include the final publisher proof-corrections or journal pagination.

Citation for the published paper:

Höök, M., Sivertsson, A. \& Aleklett, K.

"Validity of the fossil fuel production outlooks in the IPCC Emission Scenarios" Natural Resources Research, 2010, Vol. 19, Issue 2: 63-81

URL: http://dx.doi.org/10.1007/s11053-010-9113-1

Access to the published version may require subscription. 
Published in Natural Resources Research

Volume 19, Issue 2, June 2010, Pages 63-81

doi:10.1007/s11053-010-9113-1

\title{
Validity of the fossil fuel production outlooks in the IPCC Emission Scenarios
}

\author{
Mikael Höök $^{1 *}$, Anders Sivertsson ${ }^{*}$, Kjell Aleklett ${ }^{*}$ \\ Uppsala University, Global Energy Systems, Department of physics and \\ astronomy, Box 535, SE-751 21, Lägerhyddsvägen 1, Sweden \\ http://www.fysast.uu.se/ges
}

\begin{abstract}
Anthropogenic global warming caused by $\mathrm{CO}_{2}$ emissions is strongly and fundamentally linked to future energy production. The Special Report on Emission Scenarios (SRES) from 2000 contains 40 scenarios for future fossil fuel production and is used by the IPCC to assess future climate change. Previous scenarios were withdrawn after exaggerating one or several trends. This study investigates underlying assumptions on resource availability and future production expectations to determine whether exaggerations can be found in the present set of emission scenarios as well.

It is found that the SRES unnecessarily takes an overoptimistic stance and that future production expectations are leaning towards spectacular increases from present output levels. In summary, we can only encourage the IPCC to involve more resource experts and natural science in future emission scenarios. The current set, SRES, is biased toward exaggerated resource availability and unrealistic expectations on future production outputs from fossil fuels.
\end{abstract}

Keywords: SRES, emission scenarios, future fossil fuel production

\footnotetext{
${ }^{1}$ Corresponding author: Mikael.Hook@ fysast.uu.se, Fax: +46 18-4713513, Phone: +46 18-4717643
} 


\section{Introduction}

Over $80 \%$ of all the primary energy in the world is produced from fossil fuels (IEA, 2008a). Oil accounts for over 35\%, coal for $26 \%$ and natural gas for $21 \%$ (IEA, 2008a). For over a century, fossil fuels have powered the industrialized world and the economic growth, and will reasonably continue to do so for a long period of time.

Energy production is also the dominating source of anthropogenic greenhouse gasses (GHG), particularly carbon dioxide. In 2006, over 28 billion tons of $\mathrm{CO}_{2}$ were emitted due to fossil fuel consumption (IEA, 2008a). Around 57\% of all global anthropogenic GHGs derive from fossil fuel combustion, with energy supply as the largest contributing sector (Figure 1). Consequently, anthropogenic global warming caused by GHG emissions is strongly and fundamentally linked to future energy production. Studies of the future energy use and production are vital for understanding future $\mathrm{GHG}$ emissions.

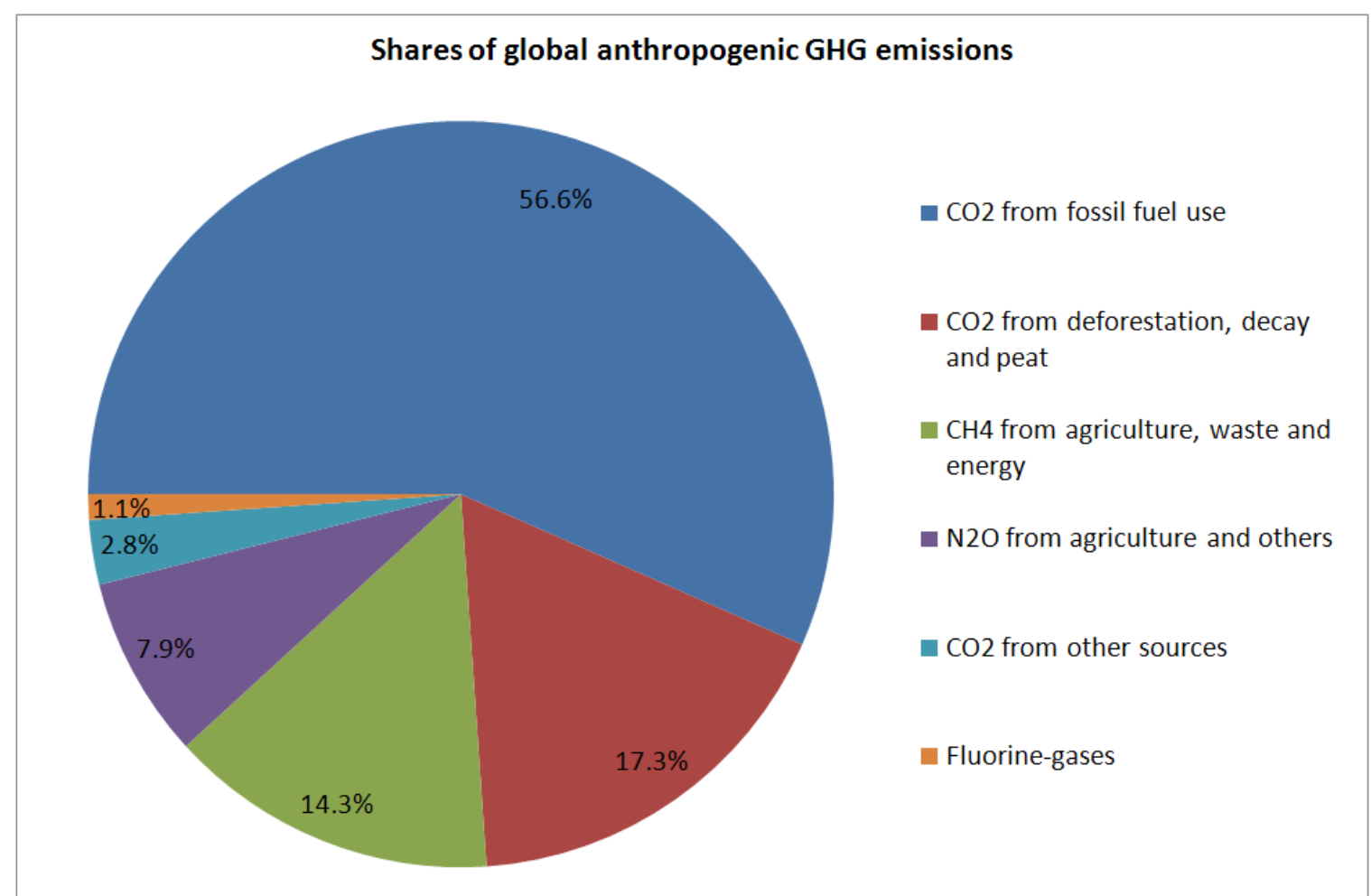

Figure 1: Shares of total GHG emissions. CO2 from fossil fuel use is dominating in terms of emissions. This strongly links energy production to GHG emissions and ultimately anthropogenic climate change to assumptions about future fossil fuel production. Modified from: IPCC (2007)

No resource is as fundamental to society as energy. In fact, energy may be seen as an ultimate and irreplaceable resource. Furthermore, energy sources must by definition provide more energy than they consume during extraction/production. This was beautifully expressed by Hubbert (1982): "there is a different and more fundamental cost that is independent of the monetary price. That is the energy cost of exploration and production. So long as oil is used as a source of energy, when the energy cost of 
recovering a barrel of oil becomes greater than the energy content of the oil, production will cease no matter what the monetary price may be".

Energy security, including oil depletion and implications of fossil fuel scarcity, and climate change has often been identified as two major challenges for the 21st century. Nel and Cooper (2008) recognize something of a paradox, as energy constraints pose a threat to economic growth, while continued use of fossil fuels would be the dominant driver of global warming. Despite awareness of fossil fuel exhaustion and the common knowledge about the finite supply of oil, gas and coal, physical resource availability is generally not used for long-term planning purposes. Energy is commonly treated as a limitless exogenous input to economic planning with the result that energy demand is well defined, but disconnected from the physical and logistical realities of supply (Nel and Cooper, 2008).

\subsection{Climate change and fossil fuel production peaking}

The Special Report on Emission Scenarios (SRES) is the basis for future GHG emissions in IPCC climate models (SRES, 2000). It features a set of scenarios, which are not compatible with the possibility that the recoverable volumes of fossil fuels and reasonable extraction rates may rule out several scenarios as physically impossible. Despite the obvious relevance of peak oil to future anthropogenic emissions it has received little attention in the climate change debate (Kharecha and Hansen, 2008).

Laherrere (2001) compared the IPCC emission scenarios with technical data and found them overly optimistic on future oil supply, both regarding conventional and unconventional oil. Sivertsson (2004) showed major anomalies between all the 40 emission scenarios and future oil and gas production and discoveries, using updated methodology and data derived from Campbell and Sivertsson (2003).

Rutledge (2007) expanded this analysis by including coal and came to the conclusion that the cumulative energy production and $\mathrm{CO}_{2}$ emissions from coal, oil and gas would be less than any of the IPCC emission scenarios. Studies on future coal production levels (Energywatch Group, 2007; Mohr and Evans, 2009) and coal-to-liquids (Milici, 2009; Höök and Aleklett, 2009c), are also in disagreement with many of scenarios in SRES.

An introduction to peak oil and the limits on available oil for extraction together with general overview of unconventional fossil fuels and investigations of resulting GHG emissions were done by Brecha (2008). Similar studies were made by Kharecha and Hansen (2008) and Nel and Cooper (2008).

\subsection{Aim of this study}

The target of this study is to examine the future production of fossil fuels in the IPCC emission scenarios (SRES, 2000). This will be done by quantifying what production capacities that would be required in reality to realize the emission scenarios. Can recent trends in world fossil fuel production be used to rule out some of the emission scenarios? In addition, we will also investigate the fundamental assumptions regarding future fossil fuel production in SRES and compare it with scientific methodology regarding reasonable future production trajectories. Future production cannot solely be determined by geological availability. In summary, we wonder whether the scientific evidence for 
resource depletion and its impacts and influence on future production have been incorporated within the SRES scenarios.

Almost two decades of historical data are now available and can be used to check how well the production scenarios agree with actual reality. Some of the scenarios can also be ruled out from mismatch with actual reality.

Both Brecha (2008) and Kharecha and Hansen (2008) argue that despite limited available fossil fuel amounts, the resulting emissions will be high enough to surpass "climate protection guardrails" and spend significant time on debating man-made climate change. This study will not pursue any such discussions and strictly focus on the validity of the future energy production part of the emission scenarios. However, if assumptions regarding the most dominating source of GHG are shown to be flawed it will naturally have repercussions on the validity of the climate change projections derived from models using those emission scenarios as input. Poor input gives poor output as a fundamental guiding principle in modelling.

\section{The Special Report on Emission Scenarios (SRES)}

The World Meteorological Organization (WMO) and the United Nations Environment Program (UNEP) established the Intergovernmental Panel on Climate Change (IPCC) in 1988. Its task is to assess scientific, technical and socio-economic information relevant for understanding anthropogenic climate change. The results have been published in several assessment reports and some special reports over the years (IPCC 1990; 1995; 2001; 2007). The IPCC has been using a set of scenarios, describing future development of society and emissions, to assess future climate change. The first set was published in 1990, followed by subsequent sets in 1992 and 2000. Titles, methods, classifications, assumptions have all changed over time and this has been reviewed by Girod et al (2009).

All of the 1992 scenarios where found to exaggerate one or more current climate and economic trends, leading to correspondingly exaggerated atmospheric greenhouse gas concentrations (Gray, 1998). Revisions were obviously needed and the current scenario set is called the Special Report on Emission Scenarios (SRES) and were published in 2000. It is the basis for the majority of long-term climate change projections, including those of the current Fourth Assessment Report (IPCC, 2007).

SRES (2000) describes 40 scenarios and calculates the greenhouse gas emissions associated with those scenarios. The scenarios are based on literature reviews, development of narrative storylines and the quantification of these story lines with the help of six integrated models from different countries. SRES illustrates that the future emissions, even in the absence of explicit environmental policies, very much depend on the choices that people make, how economies are structured, which energy sources that are preferred and how people use available land resources.

IPCC state that "they represent pertinent, plausible, alternative futures" and derive from a descriptive and open-ended methodology that aims to explore alternative futures (SRES, 2000). The emission scenarios are claimed to be neither predictions nor forecasts, even though they are commonly used as such. Additionally, no probabilities or likelihoods are assigned to any of the scenarios. All scenarios are equally sound and valid, which was required by the Terms of Reference (SRES, 2000).

The equal probability of each emission scenario is a rather peculiar assumption. In any event, this cannot be the case, since the range is due to a combination of component 
ranges of uncertainty, and thus the extremes of this range must be less probable than the central estimate (Jones, 2001). Additional discussion on the communicative issues and uncertainties with SRES can be found in Schenk and Lensink (2007). Fossil fuel combustion, the main source of anthropogenic GHG emissions, as well as future production, can be modelled by probabilistic methods (Kontorovich, 2009), making claims of equal probability for both high and low resource/production scenarios appear questionable. "Equally valid scenarios" rather materializes as an attempt to assign unjustifiably high weight to more extreme visions compared to reasonable outlooks.

The emissions scenarios are used as an input to various climate models in order to depict how the climate may change under various forms of anthropogenic emissions. Some outcomes are more desirable than others, but the equal probability assumption can act as an obstacle. Planners and engineers, who need to make decisions based on the impacts of climate change, must have a grasp of the inherent uncertainties in the guiding projections as well as the probabilities of the different outcomes. Further discussion on how to go from science to planning and policy making can be found in Walsh et al. (2004) or Green et al. (2009).

\subsection{Scenario overviews}

Each of the participating modelling teams behind the emission scenarios used computer models and experience considering long-range development of economic, technological and environmental systems to generate quantifications of the storylines, which develop the different scenarios. To simplify the procedure of depicting alternative future developments, each of the four scenario families is described by a specific storyline. The writing teams formulated the storylines in a process that identified driving forces, key uncertainties, possible scenario families and their logic. Within each scenario family different variations of global and regional development and their implications for global greenhouse gas emission are explored. The different modelling teams can be seen in Table 1. There is no business-as-usual scenario or disaster scenario and it was also decided that possible surprises, such as a new world war or major depression, should not be considered. This has been described as a built-in linear logic and utopian thought (Hjerpe and Linnér, 2008).

Closer discussions on the actual models and the concepts they rely on have been done by van Ruijven et al. (2008). The energy ladder, i.e. a simplified substitution-based concept, as well as the environmental Kuznetz curve, i.e. a U-shaped relation between economic development and environmental impact, are generally and consistently used in the SRES scenarios. However, van Ruijven et al. (2008) stress that the models might need to be reformulated to better capture the dynamics of development, especially as the SRES only depict the world in four regions and uses a limited set of socioeconomic and energy data.

Further analysis of the assumptions regarding demographics, economics and social development is beyond the scope of this study. Market exchange rates (MER) or Purchasing Power Parity (PPP) and the significant economic differences it leads over the long projection time has been discussed by Castles and Henderson (2003), Tol (2006), and van Vuuren and O'Neill (2006). McKibbin et al. (2007) show that MER terms can lead to more than $40 \%$ higher emission projections compared to estimated based on PPP. 
Table 1: The six modelling teams that developed the 40 SRES scenarios.

\begin{tabular}{|l|l|l|}
\hline Abbrevation & \multicolumn{1}{|c|}{ Full Name } & \multicolumn{1}{c|}{ Origin } \\
\hline AIM & Asian Pacific Integrated Model & $\begin{array}{l}\text { National Institute of Environmental } \\
\text { Studies (NIES), Japan }\end{array}$ \\
\hline ASF & $\begin{array}{l}\text { Atmospheric Stabilization } \\
\text { Framework Model }\end{array}$ & ICF Consulting, USA \\
\hline IMAGE & $\begin{array}{l}\text { Integrated Model to Assess the } \\
\text { Greenhouse Effect }\end{array}$ & $\begin{array}{l}\text { National Institute for Public Health } \\
\text { and Hygiene (RIVM), Netherlands }\end{array}$ \\
\hline MARIA & $\begin{array}{l}\text { Multiregional Approach for } \\
\text { Resource and Industry Allocation }\end{array}$ & Science University of Tokyo, Japan \\
\hline MESSAGE & $\begin{array}{l}\text { Model of Energy Supply Strategy } \\
\text { Alternatives and their General } \\
\text { Environmental Impact }\end{array}$ & $\begin{array}{l}\text { International Institute of Applied } \\
\text { Systems Analysis (IIASA), Austria }\end{array}$ \\
\hline MINICAM & $\begin{array}{l}\text { The Mini Climate Assessment } \\
\text { Model }\end{array}$ & $\begin{array}{l}\text { Pacific Northwest National } \\
\text { Laboratory (PNNL), USA }\end{array}$ \\
\hline
\end{tabular}

The SRES storyline titles have been kept simple: A1, A2, B1 and B2. They can be shown very straightforwardly in a two-dimensional tree, which shows the global-regional focus and the economic-environmental orientation (Figure 2). Closer description of the scenario families can be found in SRES (2000).

The four storylines and scenario families describe future worlds that are wealthier compared to the current world. It is important to notice that they do not include additional climate initiatives such as policies to limit GHG gases or to adapt to the expected climate change. These preferences features energy systems and this leads to a huge variety of corresponding GHG emissions.

The A1 storyline and scenario family describes a future world of very rapid economic growth, low population growth and the rapid implementation of new and more efficient technologies. The key plots are convergence among regions, capacity building, and increased cultural and social interactions with a significant reduction in the difference in per capita income. The A1 family is the largest and branches out in several subfamilies, each exploring an alternative future with other preferences.

The A2 family contains visions of a very heterogeneous world. The key scheme is self-reliance and preservation of local identities and cultures. Fertility patterns across the globe converge very slowly, which results in high population growth. Economic development is primarily focused on regional growth and per capita economic growth and technology change is more fragmented and slower than in other scenario families.

The B1 scenario family describes a convergent world with the same low population as in the A1 storyline, but with rapid changes in economic structures toward a service and information economy, with reductions in material intensity, and the implementation of clean and resource-efficient technologies. The emphasis is on global solutions to economic, social and environmental sustainability, including improved equity, but without additional climate initiatives.

Finally, the B2 scenario family describes a world in which the emphasis is on local solutions to economic, social and environmental sustainability. It results in a world with moderate population growth, intermediate economic growth and less and more diverse technological change than in the B1 and A1 storylines. B2 is oriented toward 
environmental protection and social equity, but also focuses on local and regional initiatives.

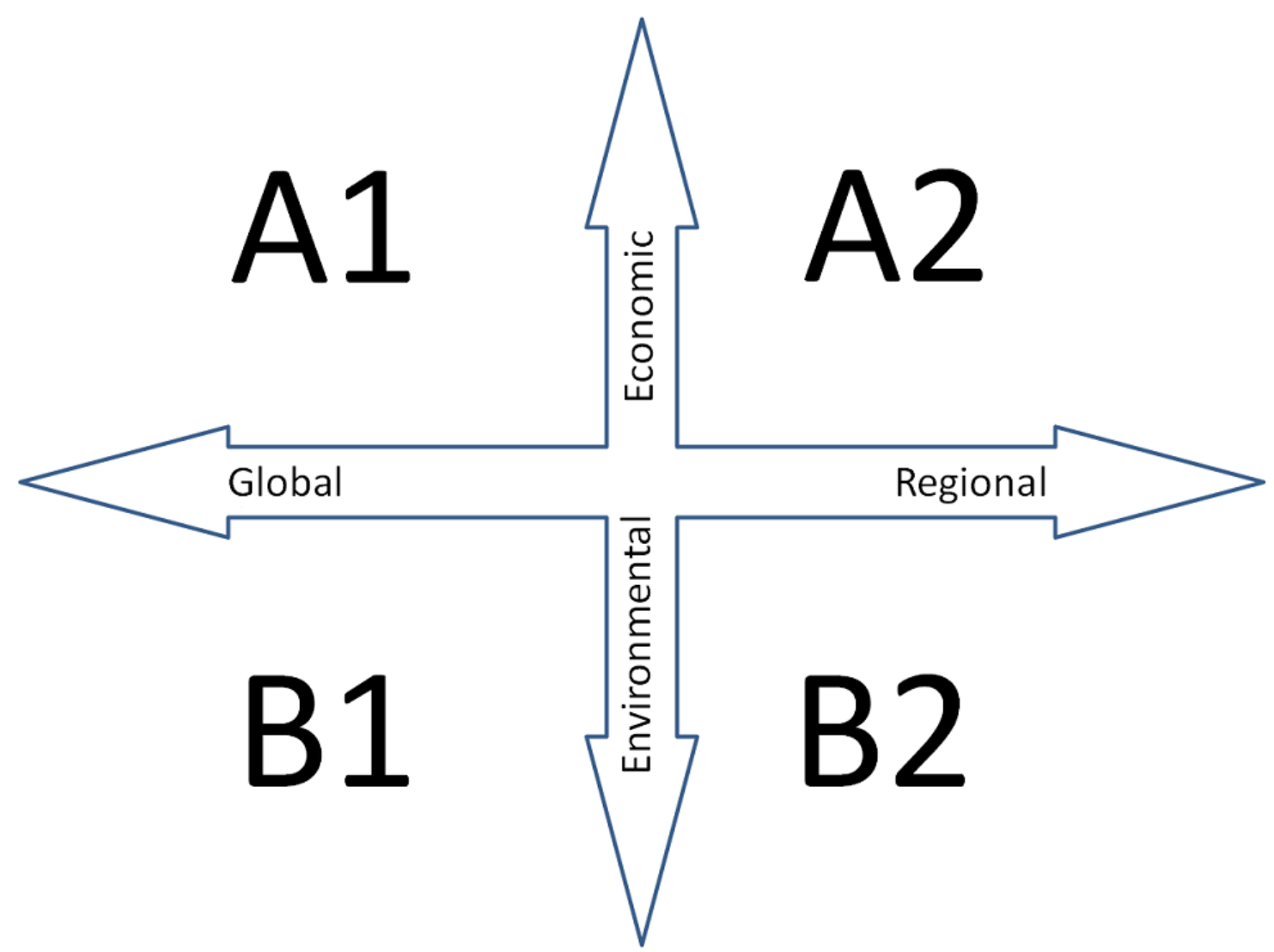

Figure 2. Schematic illustration of the SRES scenarios. The four scenario families are shown, very simplistically, as branches of a two-dimensional tree. Each scenario is based on a common specification of the main driving forces such as population, economy, technology, energy, land-use and agriculture. Adapted from SRES (2000)

All qualitative and quantitative properties of scenarios belonging to the same family were set to match the corresponding features of the underlying storyline. Together, 26 scenarios were harmonized to have the same assumptions about global population and GDP development. The remaining 14 scenarios explore alternative interpretations of the four scenario storylines, such as different rates of economic growth and variations of population growth (Sivertsson, 2004; SRES, 2000). 
Table 2. Main characteristics of development in different scenario families and groups, as applied to harmonized scenarios. Adapted from SRES (2000)

\begin{tabular}{|c|c|c|c|c|c|c|c|}
\hline Family & \multicolumn{4}{|c|}{ A1 } & A2 & B1 & B2 \\
\hline Subgroup & $A 1 C$ & $A 1 G$ & $A 1$ & $A 1 T$ & $A 2$ & B1 & $B 2$ \\
\hline $\begin{array}{l}\text { Population } \\
\text { growth }\end{array}$ & Low & Low & Low & Low & High & Low & Medium \\
\hline GDP growth & Very high & $\begin{array}{l}\text { Very } \\
\text { high }\end{array}$ & $\begin{array}{l}\text { Very } \\
\text { high }\end{array}$ & $\begin{array}{l}\text { Very } \\
\text { high }\end{array}$ & Medium & High & Medium \\
\hline Energy use & Very high & $\begin{array}{l}\text { Very } \\
\text { high }\end{array}$ & $\begin{array}{l}\text { Very } \\
\text { high }\end{array}$ & High & High & Low & Medium \\
\hline $\begin{array}{l}\text { Land-use } \\
\text { changes }\end{array}$ & $\begin{array}{l}\text { Low- } \\
\text { medium }\end{array}$ & $\begin{array}{l}\text { Low- } \\
\text { medium }\end{array}$ & Low & Low & $\begin{array}{l}\text { Medium- } \\
\text { high }\end{array}$ & High & Medium \\
\hline $\begin{array}{l}\text { Resource } \\
\text { availability }\end{array}$ & High & High & Medium & Medium & Low & Low & Medium \\
\hline $\begin{array}{l}\text { Technological } \\
\text { development }\end{array}$ & Rapid & Rapid & Rapid & Rapid & Slow & Medium & Medium \\
\hline $\begin{array}{l}\text { Change } \\
\text { favouring }\end{array}$ & Coal & $\begin{array}{ll}\text { Oil } & \& \\
\text { Gas } & \end{array}$ & Balanced & $\begin{array}{l}\text { Non- } \\
\text { fossils }\end{array}$ & Regional & Efficiency & $\begin{array}{l}\text { "Dynamics } \\
\text { as usual" }\end{array}$ \\
\hline
\end{tabular}

\section{Resource depletion and future production}

All fossil fuels are finite and non-renewable natural resources, i.e. their deposits are limited either physically or economically (Suslick and Machado, 2004). This comes from the simple fact that it takes millions of years for fossil fuels to form and they are rapidly extracted, making it impossible for the rate of creation to keep up with the rate of extraction). Consequently, fossil fuels must be subjected to depletion.

Furthermore, French mathematician Verhulst (1838) reasoned that, any population subject to growth would ultimately reach a saturation level (usually described as the carrying capacity) and as a characteristic of the environment, that forms a numerical upper bound on the growth process. The resource peak theory has strong theoretical connections to such ideas and growth phenomena in biology, where an intrinsic limit determined by nature eventually will prevent further growth. For fossil fuels it is impossible to extract more than geologically available, and natural laws will also put limits on the extraction rates.

Hubbert (1956) was among the first to propose a model for extrapolation of production curves of finite resources. His fundamental assumptions and ideas have been described by Höök and Aleklett (2009a). Although Hubbert (1956) included coal in his analysis, previous studies had already posed the question of coal. Coal and the issue of its maximum production are, contrary to common belief, an old problem and were first discussed by the national economist William Stanley Jevons in 1856 (Jevons, 1856). More recent studies have followed in the footsteps of Jevons and Hubbert and questioned the longevity of the global coal supply (Energywatch Group, 2007; Mohr and Evans, 2009).

Possible limits to growth were explored by system dynamics by the Club of Rome in their infamous report "The Limits to Growth" (Meadows et al. 1972). Sustained false statements about predictions of total depletion of vital resources and collapse of society discredited the report and made its call for fundamental policy changes and sustainability pass by relatively unnoticed (Turner, 2008). In hindsight, 30 years of reality actually agrees well with the "standard run" scenario (Turner, 2008). 
The concept on natural limits to growth and an end of the increasing production trend were later revitalized by two former oil company geologists, Colin Campbell and Jean Laherrere, when they examined the reported reserves and extrapolated discovery curves (Campbell and Laherrere, 1998). Their conclusion was that the world is facing the end of cheap and abundant oil and that the maximum oil production would occur somewhere around 2010. Aleklett and Campbell (2003) addressed more issues and created an updated model for oil depletion along with a first expansion of the analysis to cover natural gas. Numerous other studies arrive at similar dates (Bentley and Boyle, 2007). Once again, doomsday accusations and claims of undue pessimism were made, mostly from economists.

Today, the Association for the Study of Peak Oil and Gas (ASPO) has held a number of conferences on the topic and established a network for scientists and researchers concerned with the depletion of oil and other fossil resources and its consequences for mankind. Scientific evidence for a production peak has been presented in numerous occurrences by a wide array of researchers and studies. An overview of various relevant forecasting methodologies and peak oil estimates can be found in Bentley et al. (2007). Resource-constrained modelling has even been attributed as the only plausible long-term forecasting tool (Jakobsson et al., 2009).

Interest in resource depletion, mainly regarding peak oil, has grown dramatically since early 2000. From being discussed by a few concerned thinkers the topic and challenge of oil depletion have risen to the highest possible levels in short time. An influential report concluded that: "the peaking of world oil production presents the U.S. and the world with an unprecedented risk management problem" (Hirsch et al, 2005). A UK industry taskforce came to a similar conclusion when they stated that: "the risks to UK society from peak oil are greater than those routinely on the government's risk-radar at present, including terrorism" (UK Industry Taskforce on Peak Oil and Energy Security, 2008). Even the OECD energy agency, IEA, points to the unsustainable nature of continued oil dependence and the major challenges associated with increasing production levels to just above $100 \mathrm{Mb} / \mathrm{d}$ (IEA, 2008b).

Additionally, future production is a matter of more than just geological availability of a certain resource. Social acceptability, economic conditions, legal constraints and much more also affects future production of any resource. For example, it can be shown that less than one-half of the total available coal resources of the Appalachian Basin were available for mining and only one-tenth were considered economically recoverable (Ruppert et al., 2002). Höök and Aleklett (2009a, 2009b) show that restrictions play a major role in preventing significant shares of US coal from being produced and that those restrictions are not likely to be relaxed in the future. Future behaviour of restrictions and the political atmosphere they derive from are essential factors for future production.

Since fossil fuels dominate our existing energy system, they will also have to power any possible shift to renewable or other energy sources and the effect this has on fossil fuel reserves will depend largely on the size and speed of the shift, since fossil fuel energy used will be additional to that already in use (Moriarty and Honnery, 2009). 


\subsection{SRES dependence on Rogner}

Resource availability in SRES (2000) is built around the works of Rogner (1997) and Gregory and Rogner (1998), and relies on them for detailed discussion of the estimated hydrocarbon amounts. Closer discussion on fossil fuel availability can be found in SRES (2000) and Sivertsson (2004). The message of Rogner (1997) is that the vast unconventional hydrocarbon occurrences and historically observed rates of technology change would allow hundreds of years with availability of fossil energy with low longterm costs, i.e. not significantly higher than the market price of the 1990s. Rogner (1997) also states that additional occurrences beyond the common resource base makes fossil fuels appear as an almost unlimited energy source. In summary, main point of Rogner (1997) is that "the sheer size of the fossil resource base makes fossil sources an energy supply option for many centuries to come", provided that economy and technological progress are favourable.

Rogner (1997) based his conclusions on compilation of hydrocarbon resource estimates prior to 1997. Some of the prime sources are BP, World Energy Council and German Federal Institute of Geosciences, while other stems from academic studies. For conventional petroleum, Rogner (1997) states an ultimate recoverable resource base of 2800 Gigabarrels $(\mathrm{Gb})$ and the aggregated number unconventional oil occurrence is $16500 \mathrm{~Gb}$, where unconventional include heavy oil, tar sand and oil shale. Clearly, unconventional oil will have to be the main source in the long run. Comparison between Rogner (1997) and more recent estimates of available unconventional oil can be found in Greene et al. (2006).

A similar picture is given for natural gas, with only 2900 gigabarrels of oil equivalents (Gboe) as conventional gas (3100 Gboe if natural gas liquids are included) and 142000 Gboe of unconventional occurrences. Over $95 \%$ of the unconventional gas is assumed to be methane hydrates, while coal-bed methane, fractured shale, tight formation and remaining in-situ amounts only constitute minor amounts. As a result, future gas availability must be tightly connected to methane hydrates and their development.

Rogner (1997) states that drilling yet has to confirm the existence of the gas hydrates suggested by seismic surveys. Actually, few thick deposits have actually been found by drilling and generally the existence of gas hydrates is determined by no more than uncertain seismic information (Laherrere, 1999; 2000). It is also worth to notice that the resource estimates differ by three orders of magnitude (Collett and Kuuskraa, 1998). Some research is undertaken but commercial production is very far away and gas hydrates will not likely contribute to world gas production for the next 30-50 years (Collett, 2002).

For coal, Rogner (1997) highlight the many fluctuations in world reserve and resource assessments. The overview is very brief in comparison with oil and gas, mostly calling out to BGR (1980) as the main source. The total coal resource is placed at 45800 Gboe, which would equal $8744 \mathrm{Gt}$ of coal (assuming $30 \mathrm{GJ} /$ ton coal). Nearly $60 \%$ of all the coal is found in the most uncertain category.

Gregory and Rogner (1998) largely rely of the resource estimates derived by Rogner (1997) but make a few new additions with resource estimates for renewable and non-fossil fuels. A significant share of the article is devoted to speculation and 
envisioning the feasibility for future conversion technologies, ranging from fuel cells and hydrogen to unconventional hydrocarbons such as oil shale or gas hydrates.

Interestingly enough, Gregory and Rogner (1998) also mentions the "pessimistic" view on ultimate recoverable resources, represented by geologists and including Laherrere and Campbell, and the "optimistic" view, lead by economists Adelman and Lynch. Rogner, also being an energy economist, takes the optimistic side and points to the importance of unconventional hydrocarbon resources.

\subsection{SRES standpoint regarding resource depletion}

SRES (2000) mentions works of petroleum geologists Ivanhoe and Leckie (1994), Laherrere (1994) and Campbell (1997), who all questioned the size of the oil reserves and suggested that the actual recoverable volumes are smaller than expected. The claims of limited volumes of recoverable oil is dismissed by arguments from economists Adelman and Lynch (1997), which claims that "huge amounts of hydrocarbons are available in the Earth's crust" and that "estimates of declining reserves and production are incurably wrong because they treat as a quantity what is really a dynamic process driven by growing knowledge". Technological advances are also given as a reason for improved recovery and development of previously uneconomic reservoirs. The rhetoric is virtually identical to that of Rogner (1997) and Gregory and Rogner (1998). SRES unnecessary takes the "optimistic side", effectively disbanding phenomenological models derived from natural science for economic models, instead of providing a sound and more balanced view on resources availability.

\section{Fossil fuel production in SRES}

In order to picture various future outcomes, SRES (2000) assume everything from low to very high resource availability. Future resource use is dependent on future price levels (either assumed as exogenous inputs or determined endogenously in the model) and future technology capable of mining unconventional resources. All the scenario story lines show elements of utopian thinking in particular regarding future technologies capable of decoupling economic growth from energy consumption, how globalization is assumed to even out economic differences and how access to energy is rising in the future (Hjerpe and Linnér, 2008).

In SRES (2000), it is declared that the current oil industry is mature and the question of when the current reserves will start to run out is asked without being answered. High hopes are placed in unconventional oil resources such as shale oil, tar sands, bitumen and heavy oil, especially in the high tech scenarios. Natural gas is believed to have larger potential since the gas industry is less mature and much more remains to be discovered, particularly in remote areas far from infrastructure. Unconventional gas, such as coal-bed methane or gas hydrates, is expected to come into large scale production. Regarding coal, the question is assumed to be only one of economics, accessibility and environmental acceptance.

All production numbers in SRES (2000) are presented in exajoules (EJ) or zetajoules (ZJ), which are units that are hard to grasp in layman's terms. As a result, we have chosen to convert their figures to more commonly used units. For conversion, we 
have used $42 \mathrm{GJ}$ as a ton of oil equivalent and equated a barrel of oil equivalent as 6.12 GJ.

\subsection{A1 family}

Energy and mineral resources are rich in this family as rapid technological progress reduces the amount of resources needed for the same level of production and increases the economically recoverable reserves. The scenario family also has some subgroups that explore variants of this rich and technological future. A1C depicts a coal-focused future where new clean coal technologies, such as sulphur removal, have turned coal environmental-friendly with the exception of GHG emissions. A1G describes an oil and gas rich future, with a rapid transition from conventional resources to rich unconventional resources such as methane hydrates. A1T describes a non-fossil future where rapid developments of solar and nuclear technologies replace fossil fuels.

For oil, the projected production levels can be seen in Figure 3. Oil production is on average assumed to be over $100 \mathrm{Mb} / \mathrm{d}$ from 2020 to after 2100, with an intermediate peak in 2070 at $126 \mathrm{Mb} / \mathrm{d}$. The cumulative oil production of the A1 family averages just below $4000 \mathrm{~Gb}$ (Table 3).

This scenario family also contains a number of oil price assumptions, which are generally low. For example, the A1 AIM-scenarios expect a crude oil price of 43 dollars per barrel in 2020 (here expressed in 2006 dollars), later increasing to $55 \$ / \mathrm{b}$ in 2050 and 73 \$/b in 2100 (SRES, 2000). Such price projections, spanning 100 years into the future, seem dubious at best.

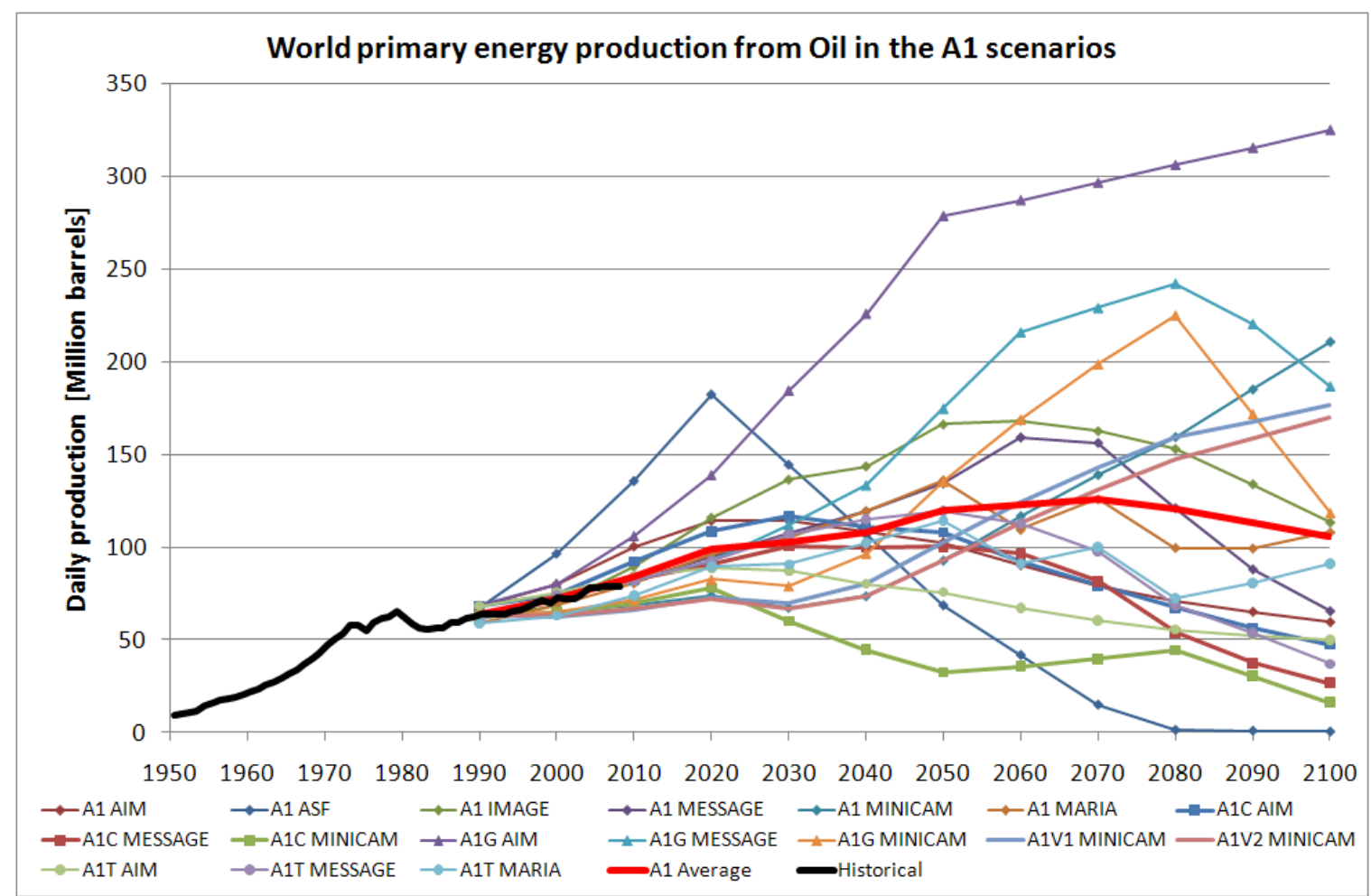

Figure 3: Projected world oil production the in Al scenario family. Production ranges from 0 to $325 \mathrm{Mb} / \mathrm{d}$, but the average scenario is a peak at $126 \mathrm{Mb} / \mathrm{d}$ in 2070. 
Expected gas and coal production in the A1 family is also high (Figure 4). Gas production in 2008 were $52 \mathrm{Mboe} / \mathrm{d}$, equal to $2768 \mathrm{Mtoe}$ (BP, 2009), which agrees reasonably well with the average of the A1 family. However, significant future hydrocarbon production increases are expected along with high cumulative production (Table 3). On average, 5500 Gboe of natural gas are expected to be produced and this implies that virtually all the conventional gas in Rogner (1997) have been depleted and almost as much taken from unconventional sources.

For coal, future production can be found in Figure 5. Massive increases in world production are generally expected and no peak at all is foreseen prior to 2100 in the average case. The cumulative production implies that more than the worlds known coal reserves have to be produced.

In summary, one can only see that this scenario family is indeed very optimistic regarding future energy production and has a built-in assumption that no constraints or limitations will apply to fossil fuel utilization prior to 2100. Full depletion of the worlds known currently fossil fuel reserves can also be expected along with significant contribution from unconventional oil and gas. A number of scenarios, such as A1 ASF with an oil peak at $182 \mathrm{Mb} / \mathrm{d}$ in 2020 or A1T Maria that phases out coal entirely in the long run, can be ruled out from disagreement with historical data.

Table 3: Cumulative hydrocarbon production 1990-2100 in the Al family

\begin{tabular}{|l|c|c|c|}
\hline \multicolumn{1}{|c|}{ Scenario name } & Oil [Gb] & Gas [Gboe] & Coal [Gboe] \\
\hline A1 AIM & 3404.7 & 7363.0 & 2601.3 \\
\hline A1 ASF & 2783.3 & 4720.8 & 8420.2 \\
\hline A1 IMAGE & 4889.9 & 3971.7 & 3663.5 \\
\hline A1 MESSAGE & 4119.4 & 5574.9 & 3098.1 \\
\hline A1 MINICAM & 4019.0 & 7895.9 & 3394.1 \\
\hline A1 MARIA & 3754.8 & 4882.2 & 1384.0 \\
\hline A1C AIM & 3335.4 & 3441.5 & 11167.9 \\
\hline A1C MESSAGE & 3026.1 & 3574.8 & 7905.5 \\
\hline A1C MINICAM & 1874.5 & 3907.8 & 9799.5 \\
\hline A1G AIM & 8294.5 & 9585.2 & 3076.1 \\
\hline A1G MESSAGE & 5623.2 & 8566.0 & 3498.5 \\
\hline A1G MINICAM & 4837.7 & 7141.0 & 6186.1 \\
\hline A1V1 MINICAM & 4001.3 & 5173.5 & 3517.4 \\
\hline A1V2 MINICAM & 3773.1 & 5065.1 & 3711.6 \\
\hline A1T AIM & 2716.3 & 5216.3 & 2022.8 \\
\hline A1T MESSAGE & 3391.9 & 4354.7 & 1906.7 \\
\hline A1T MARIA & 3199.6 & 4171.2 & 720.5 \\
\hline $\boldsymbol{A 1} \boldsymbol{A} \boldsymbol{V E R A G E}$ & $\mathbf{3 4 0 4 . 7}$ & $\mathbf{5 5 6 5 . 0}$ & $\mathbf{4 4 7 4 . 9}$ \\
\hline
\end{tabular}




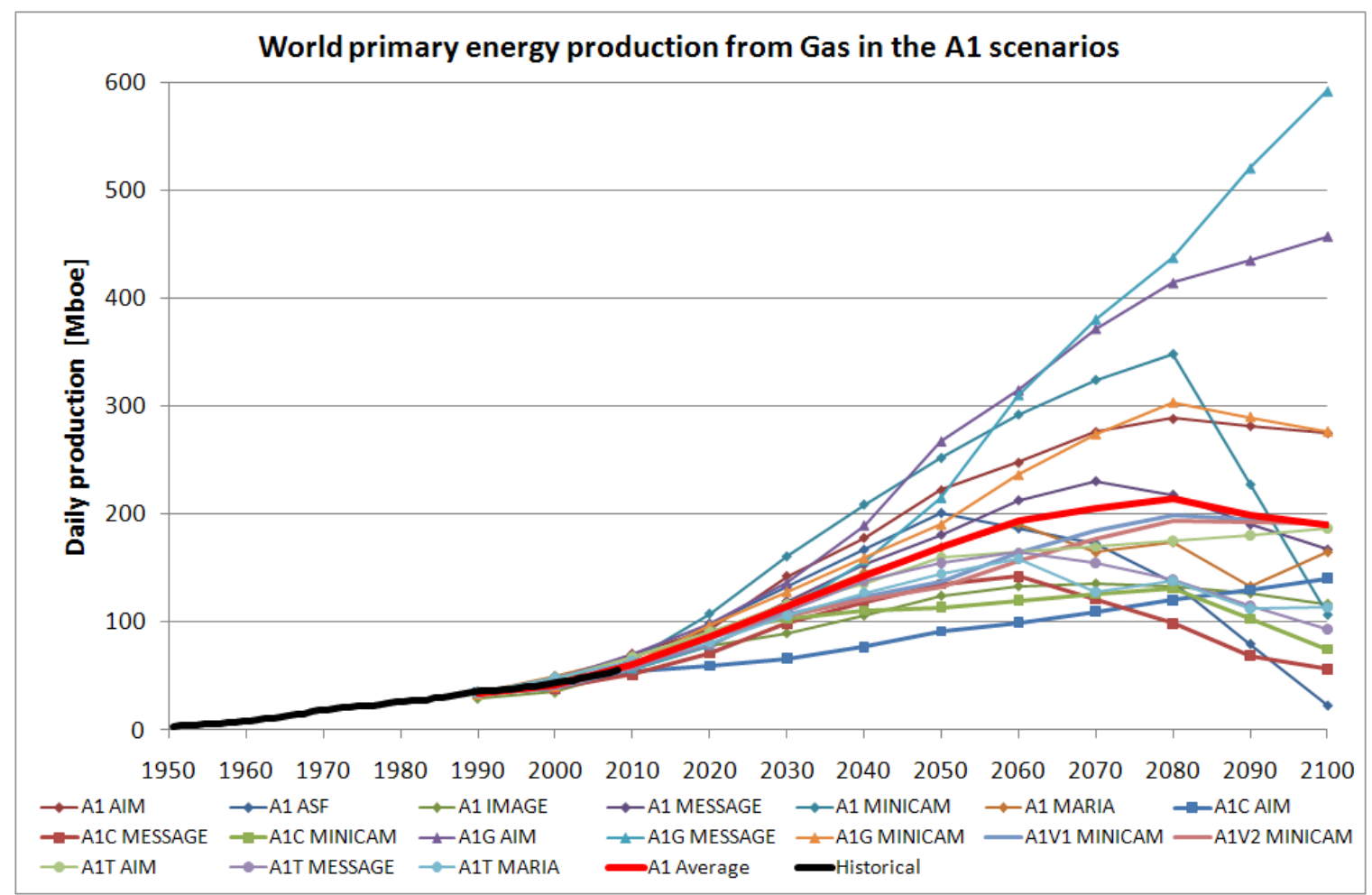

Figure 4: Projected world gas production the in Al scenario family. Production ranges from 50 to nearly $600 \mathrm{Mboeld}$ by 2100, but the average is $190 \mathrm{Mboe/d}$ peaking in 2080.

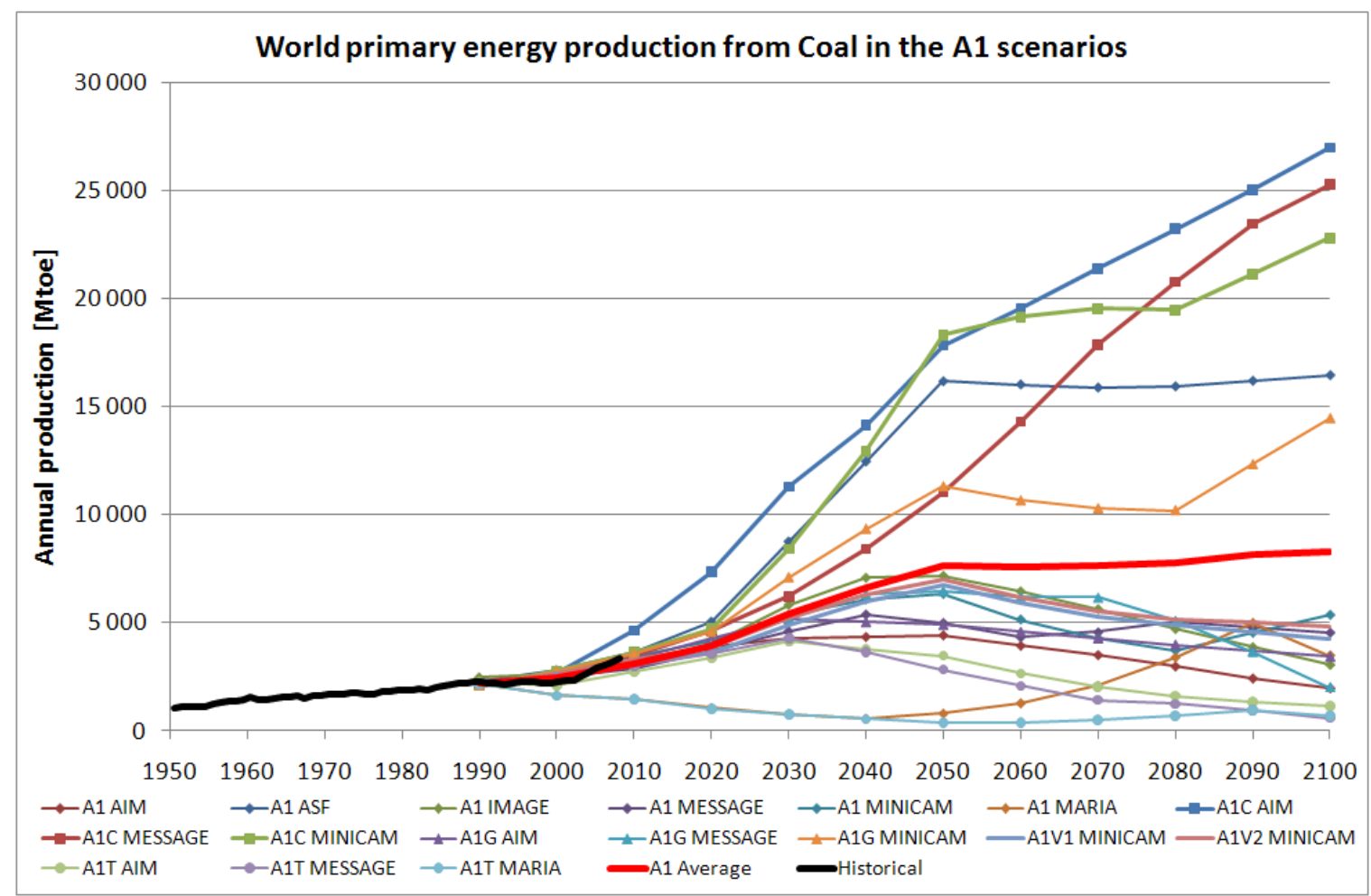

Figure 5: Projected world coal production the in Al scenario family. Production ranges from 800 to nearly 27000 Mtoe by 2100, with an average is 11000 Mtoe without a peak prior to 2100 . 


\subsection{A2 family}

This family describes a differentiated world that, compared to A1, is characterized by low trade flows, relatively slow capital stock turnover and slower technological progress. This family also depicts self-reliance in terms of resources and less weight on social, economic and cultural interactions between different regions. A2 is often used as the "business-asusual" family, where economic development without environmental concern or major attempts to reduce the gap between rich and poor countries.

Regions with rich mineral and energy supply will develop into more resourceintensive economies. Other regions with fewer resources will focus on minimizing import dependence and improve efficiency or make use of alternative inputs. The resource availability in different regions mainly determines the fuel mix used. High-income but resource-poor regions develop advanced post-fossil technologies while low-income but resource-rich regions generally rely on older fossil technology. The resource availability is generally rather conservative, and utilization is largely limited to conventional resources without venturing into the field of unconventional fuels, generally resulting in high coal consumption.

The future oil production in this family is generally high compared to present levels (Figure 9). Many scenarios foresee rapid increased up to 2020 followed by a peak, and this is reflected in the average. A2-A1 MINICAM is the exception with a production level of $222 \mathrm{Mb} / \mathrm{d}$ in 2100.The cumulative oil production between 1990 to 2100 ends up around $3000 \mathrm{~Gb}$ (Table 4), which would be enough to deplete more than the world's ultimate reserves of conventional oil before the end of the century.

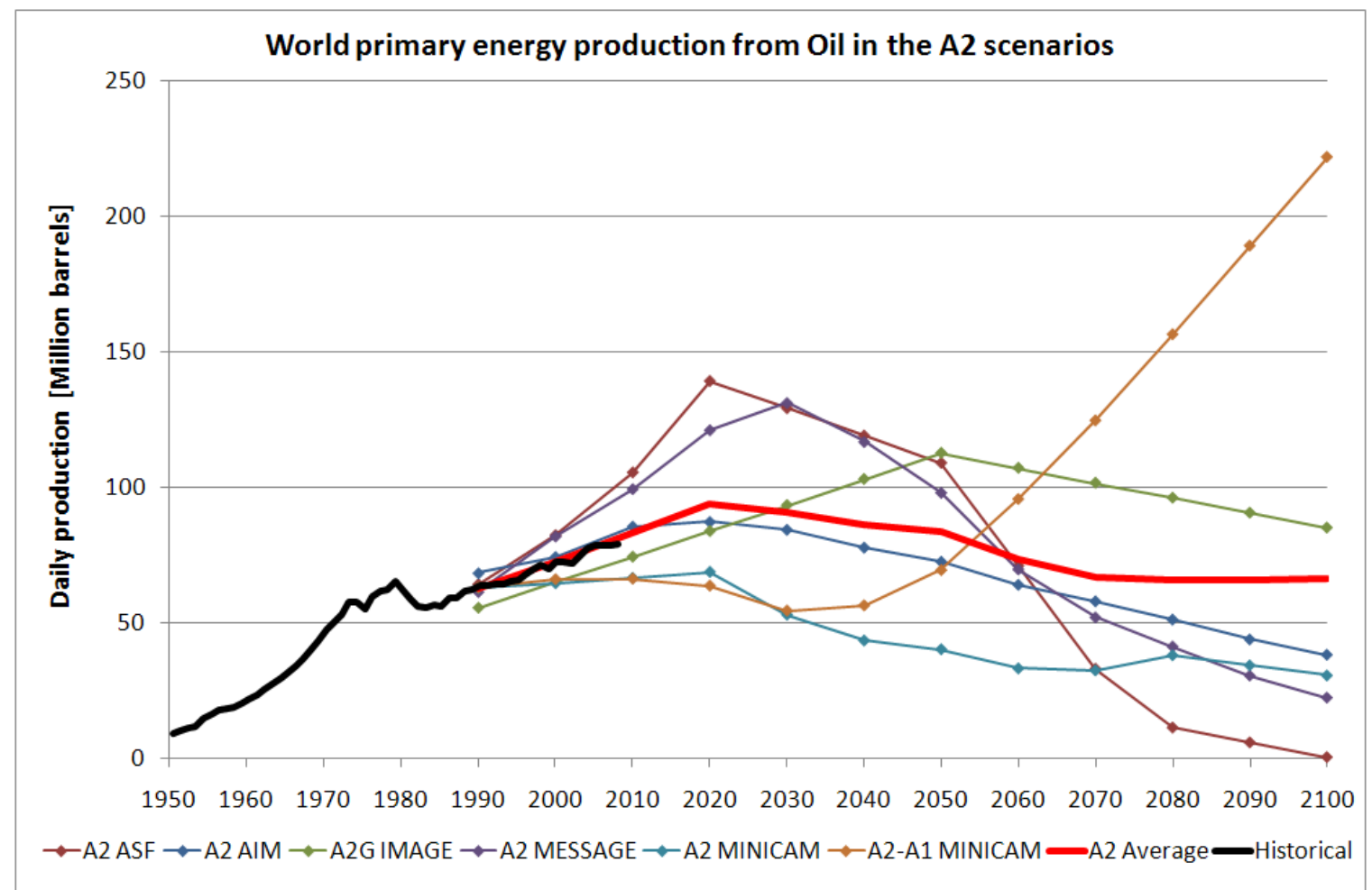

Figure 6: Projected oil production in the A2 scenarios. By 2100, production capacity range from 0 to $222 \mathrm{Mb} / \mathrm{d}$, with an average of $66 \mathrm{Mb} / \mathrm{d}$ after a peak in 2020. 
Gas and coal production is projected with generally continued increase trends throughout the rest of the century, resulting in a tripling of world gas production and roughly six times higher coal production by 2100 on average (Figure 7 and 8 ).

The coal production outlooks would put enormous pressure on the USA, Russia, China, Australia, India and South Africa as they together hold roughly $90 \%$ of the world's coal reserves and resources (BP, 2009; BGR, 2008). For example, major amounts of the Russian coal are located in the Tunguska and Lena basins in central Siberia (Thomas, 2002), and will not realistically be developed for many decades due to limited infrastructure as well as remoteness and harsh climate.

Table 4: Cumulative hydrocarbon production 1990-2100 in the A2 family

\begin{tabular}{|l|c|c|c|}
\hline \multicolumn{1}{|c|}{ Scenario name } & Oil [Gb] & Gas [Gboe] & Coal [Gboe] \\
\hline A2 ASF & 2817.9 & 4287.2 & 7641.1 \\
\hline A2 AIM & 2607.3 & 4698.8 & 7800.3 \\
\hline A2G IMAGE & 3516.8 & 6197.0 & 3527.6 \\
\hline A2 MESSAGE & 3116.2 & 3765.9 & 5128.7 \\
\hline A2 MINICAM & 1790.4 & 3216.2 & 7669.2 \\
\hline A2-A1 MINICAM & 3684.2 & 4510.9 & 3277.9 \\
\hline A2 Average & $\mathbf{2 9 2 2 . 1}$ & $\mathbf{4 4 4 6 . 0}$ & $\mathbf{5 8 4 0 . 8}$ \\
\hline
\end{tabular}

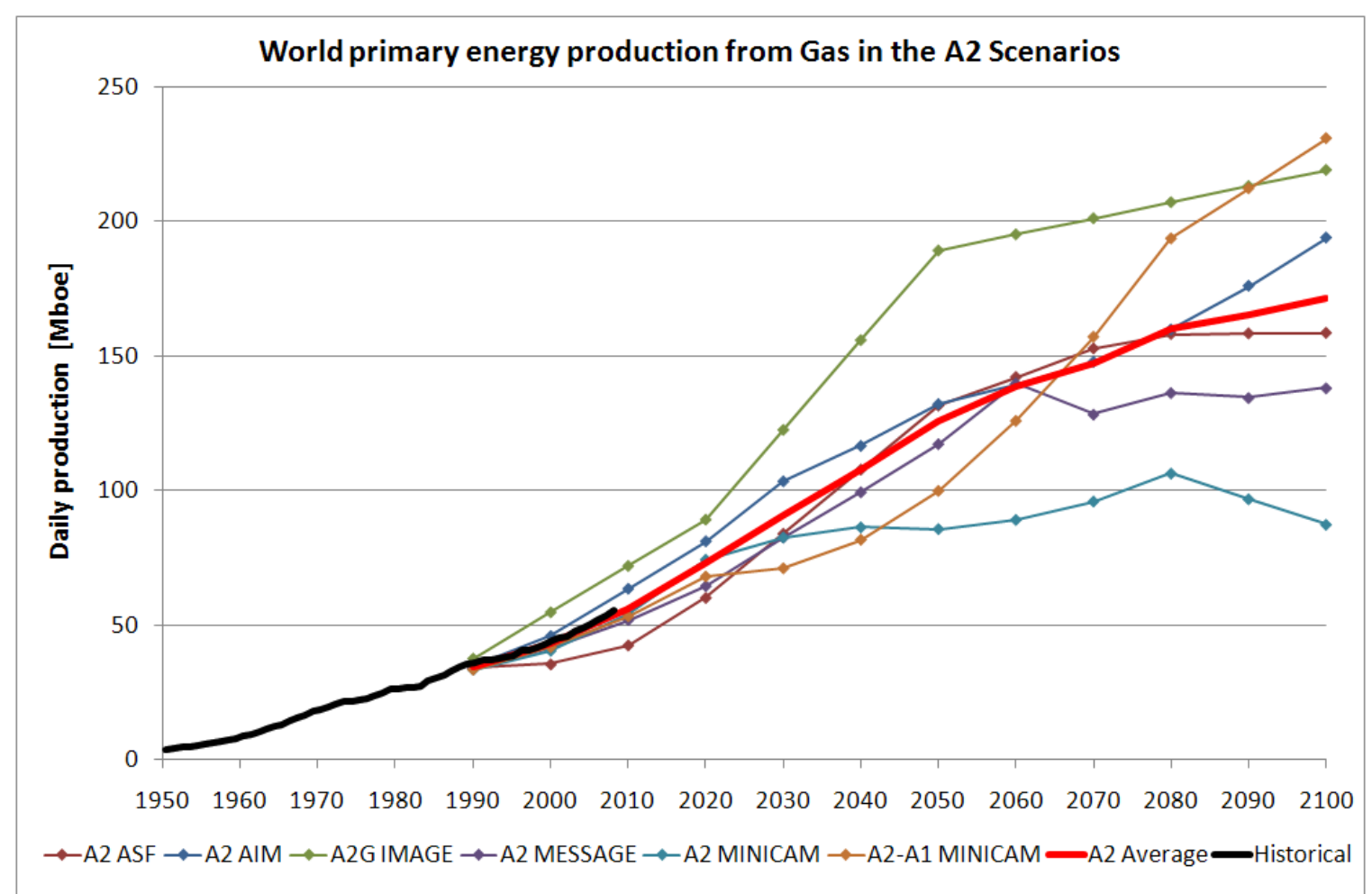

Figure 7: Projected gas production in the A2 family. No peak in sight, despite the assumption about conservative resource availability and little exploration of unconventional gas. 


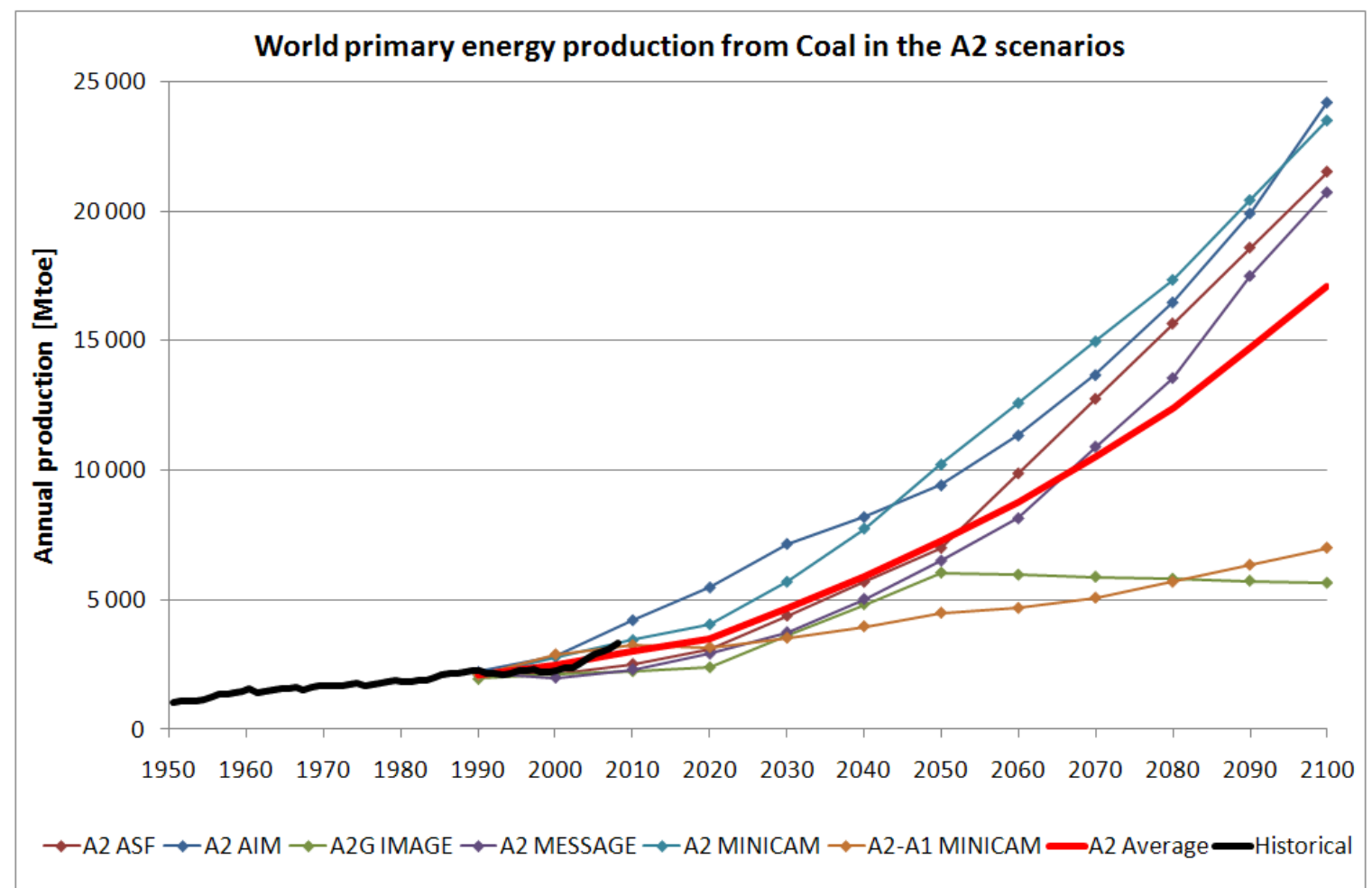

Figure 8: Projected coal production in the A2 family.

\subsection{B1 family}

The ultimately recoverable conventional and unconventional fossil resources in this scenario family follow the same resource assumption as the A2 family. However, a supposed availability of huge unconventional oil and gas supplies, with a geographic distribution widely different from conventional resources, will have a significant impact on fuel supply and trade flows in the long term.

Gregory and Rogner (1998) estimate 54\% of the world's heavy crude oil to be found in South America and mainly in the Orinoco formation in Venezuela. Additionally, $70 \%$ of the worlds tar sand and bitumen is located in Canada (Gregory and Rogner, 1998). More recent estimates make the Venezuelan and Canadian dominance even larger (World Energy Council, 2007). Only the ultimate oil shale resources in place seems to be well distributed over the globe with approximately equal shares in North and South America and Asia, while Europe and Africa is almost empty (Gregory and Rogner, 1998). In comparison, World Energy Council (2007) places nearly all the world's oil shale resources in the USA, although it is noted that information is rudimentary on many oil shale formations and that significant drillings and analytical work remains to be done. In summary, we find it questionable that the geographic distribution justifies significant impact on fuel supply and trade flows as most unconventional oil reside in a relatively limited number of countries. Additionally, the existence of unconventional resources has little to do with the likelihood of a significant contribution to future energy supply.

B1 assumed that the capital output ratio of resource exploitation is assumed to rise with increasing depletion, but this is counteracted by learning curve effects. Coal production costs are assumed to rise with increasing depth and rising labour wages but 
this offset by increased mechanization (for underground mining) and economic scale-up effects.

Cumulative production of oil and gas remains high, equal to more than full depletion of most conventional oil and gas resources, while coal is significantly lower than A1 and A2 (Table 5). Several scenarios, such as B1 ASF with an oil production of $170 \mathrm{Mb} / \mathrm{d}$ by 2020 or B1 MARIA that features monotonically decreasing coal production after 1990, can also be ruled out due to poor agreement with actual data.

Table 5: Cumulative hydrocarbon production 1990-2100 in the B1 family

\begin{tabular}{|l|c|c|c|}
\hline \multicolumn{1}{|c|}{ Scenario name } & Oil [Gb] & Gas [Gboe] & Coal [Gboe] \\
\hline B1 IMAGE & 3195.8 & 2561.6 & 2153.9 \\
\hline B1 AIM & 2560.9 & 4154.4 & 2606.4 \\
\hline B1 ASF & 2808.3 & 4168.7 & 4451.1 \\
\hline B1 MESSAGE & 2783.4 & 4041.5 & 1106.0 \\
\hline B1 MARIA & 2864.0 & 3571.9 & 533.7 \\
\hline B1 MINICAM & 2596.3 & 2699.1 & 1716.4 \\
\hline B1T MESSAGE & 2768.4 & 3573.3 & 1057.5 \\
\hline B1HIGH MESSAGE & 2809.3 & 4167.1 & 1383.8 \\
\hline B1HIGH MINICAM & 2734.4 & 5550.8 & 2095.9 \\
\hline B1 $\boldsymbol{A} \boldsymbol{V E R A G E}$ & $\mathbf{2 7 9 1 . 2}$ & $\mathbf{3 8 3 2 . 1}$ & $\mathbf{1 9 0 0 . 5}$ \\
\hline
\end{tabular}

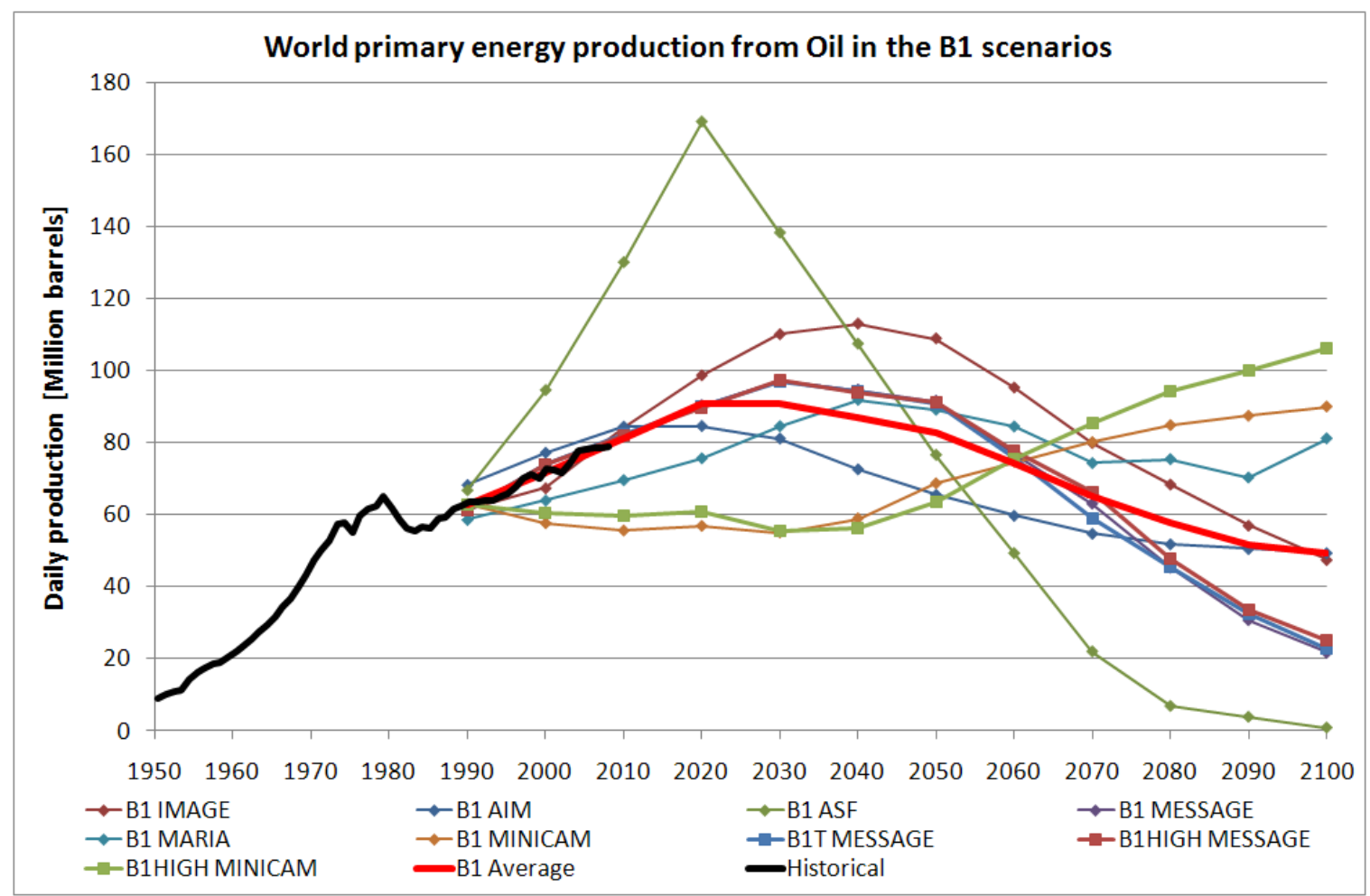

Figure 9: Projected oil production in the B1 scenario family. 


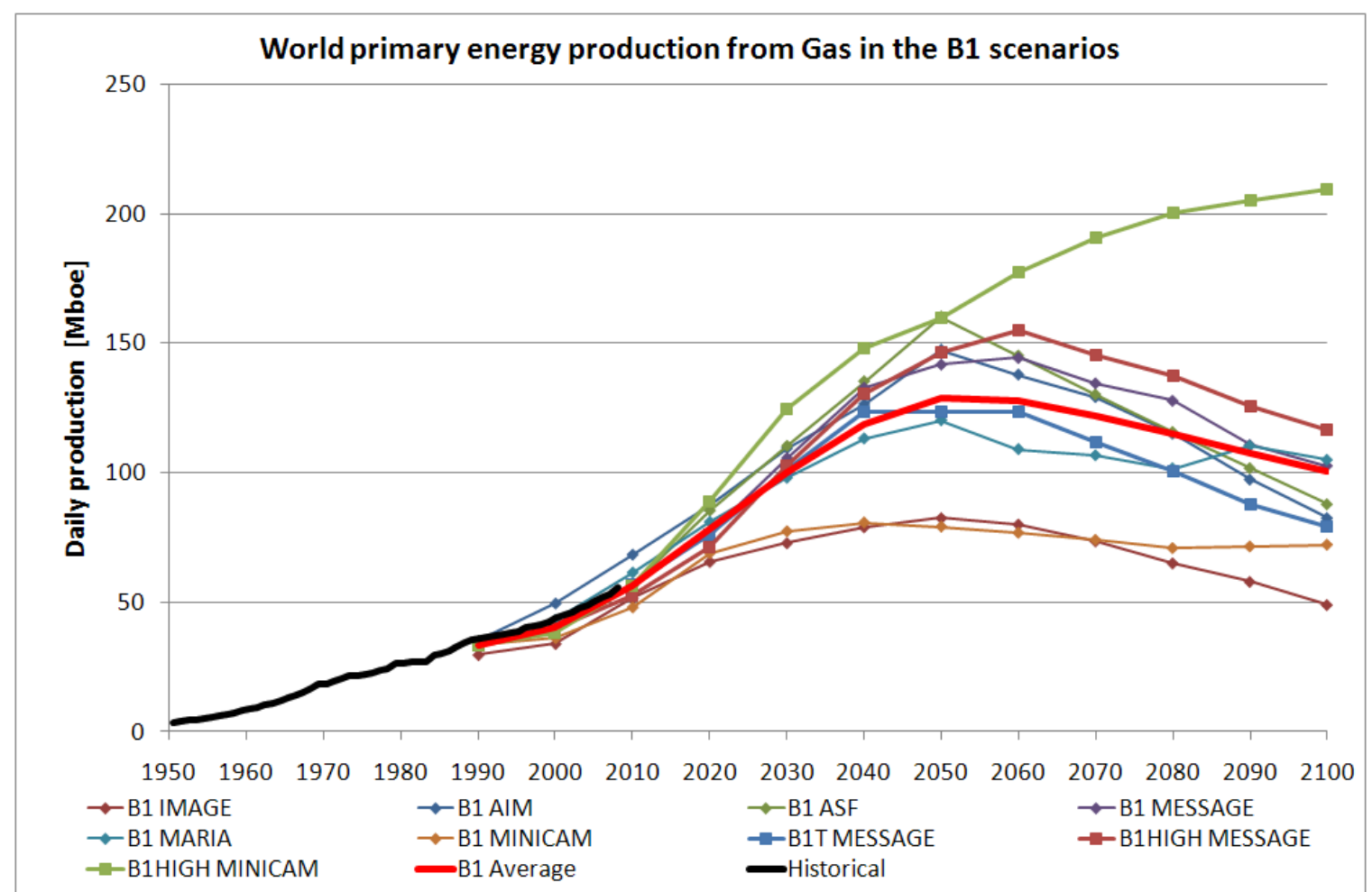

Figure 10: Projected gas production in the B1 scenario family.

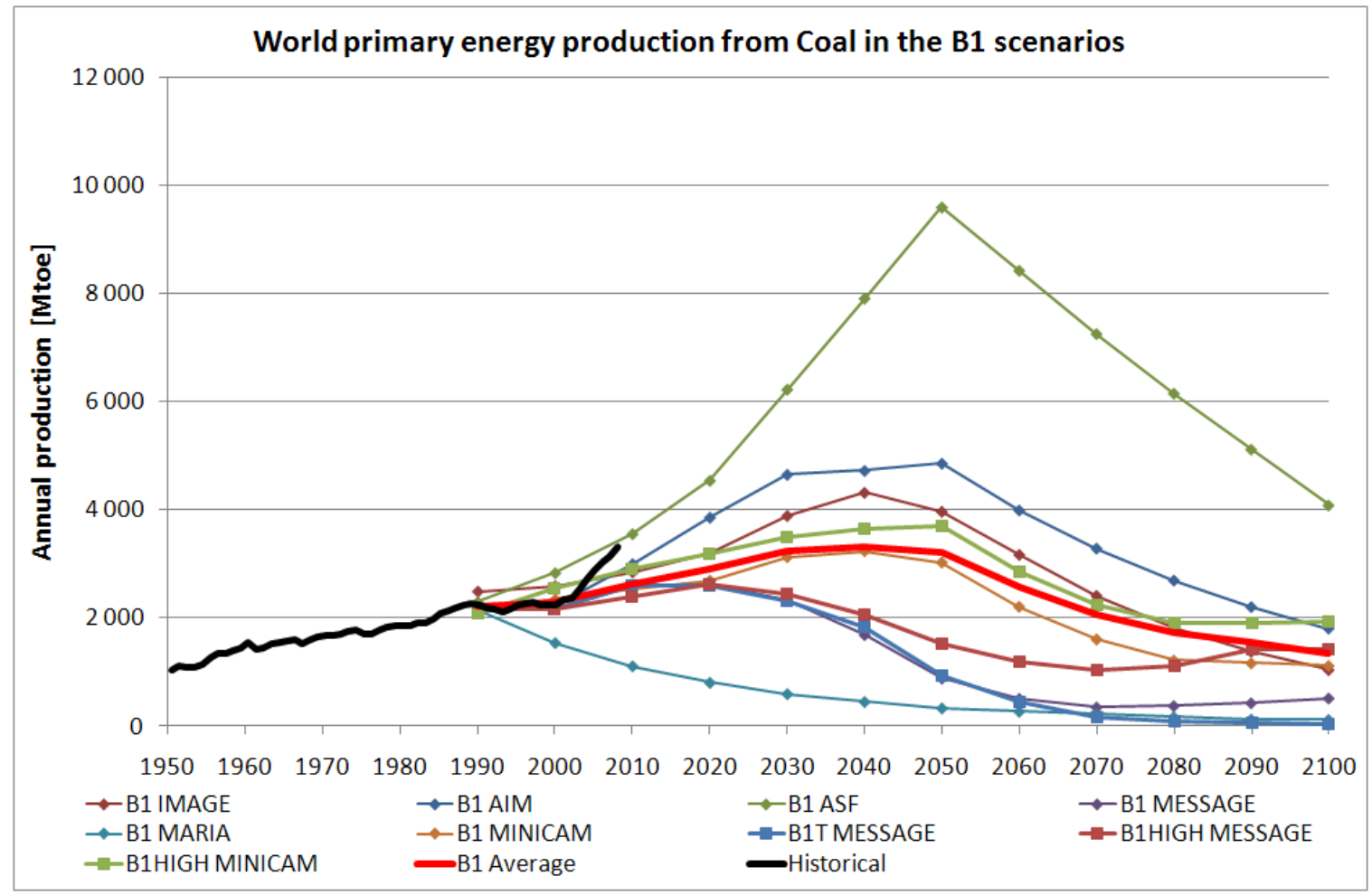

Figure 11: Projected coal production in the B1 scenario family. 


\subsection{B2 family}

Here the available fossil energy is assumed to be conservative. The availability of oil and gas expands only gradually and it not extended much beyond current conventional and unconventional reserves (as of late 1990s). However, coal is assumed to be abundant. Overall this results in relatively limited energy options for the world.

Oil production is, on average, assumed to be at present levels through the rest of the century with a peak in 2020 followed by a very gentle decline (Figure 12). The cumulative oil production (Table 6) is equivalent to approximately the ultimate conventional reserves. Gas and coal features much higher production levels than present (Figure 13 and 14).

Table 6: Cumulative hydrocarbon production 1990-2100 in the B2 family

\begin{tabular}{|l|c|c|c|}
\hline \multicolumn{1}{|c|}{ Scenario name } & Oil [Gb] & Gas [Gboe] & Coal [Gboe] \\
\hline B2 MESSAGE & 3178.4 & 4698.4 & 2063.4 \\
\hline B2 AIM & 2832.8 & 4521.6 & 3922.9 \\
\hline B2 ASF & 2822.4 & 3872.9 & 5393.7 \\
\hline B2 IMAGE & 2016.1 & 3413.3 & 2930.0 \\
\hline B2 MARIA & 2848.9 & 3297.4 & 3115.6 \\
\hline B2 MINICAM & 3713.4 & 4187.0 & 2976.1 \\
\hline B2HIGH MINICAM & 1833.3 & 3125.3 & 7247.9 \\
\hline B2C MARIA & 2947.9 & 3383.1 & 4177.2 \\
\hline B2 $\boldsymbol{A} \boldsymbol{V E R} \boldsymbol{A G E}$ & $\mathbf{2 7 7 4 . 1}$ & $\mathbf{3 8 1 2 . 4}$ & $\mathbf{3 9 7 8 . 4}$ \\
\hline
\end{tabular}

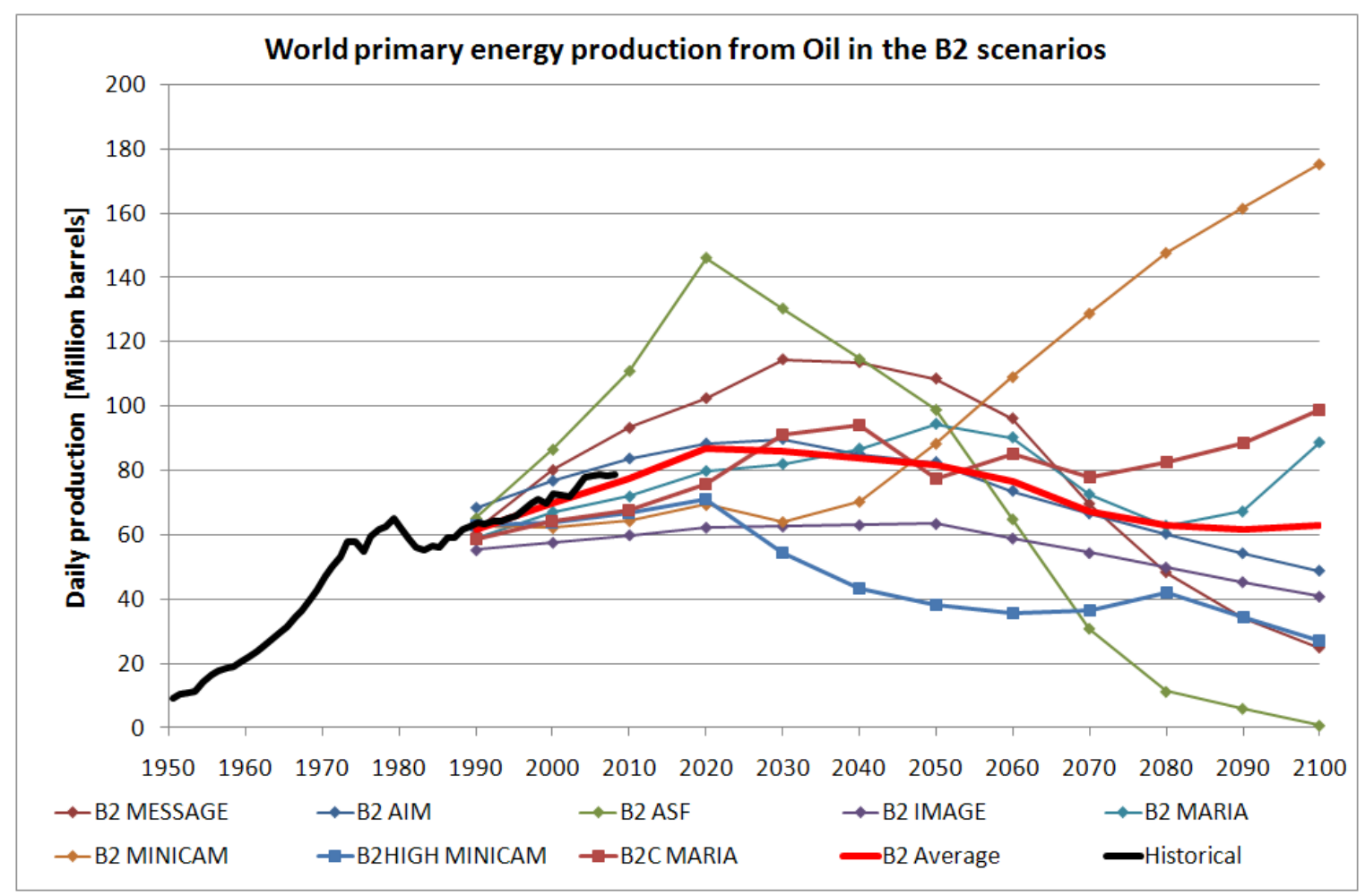

Figure 12: Projected oil production in the B2 scenario family. 


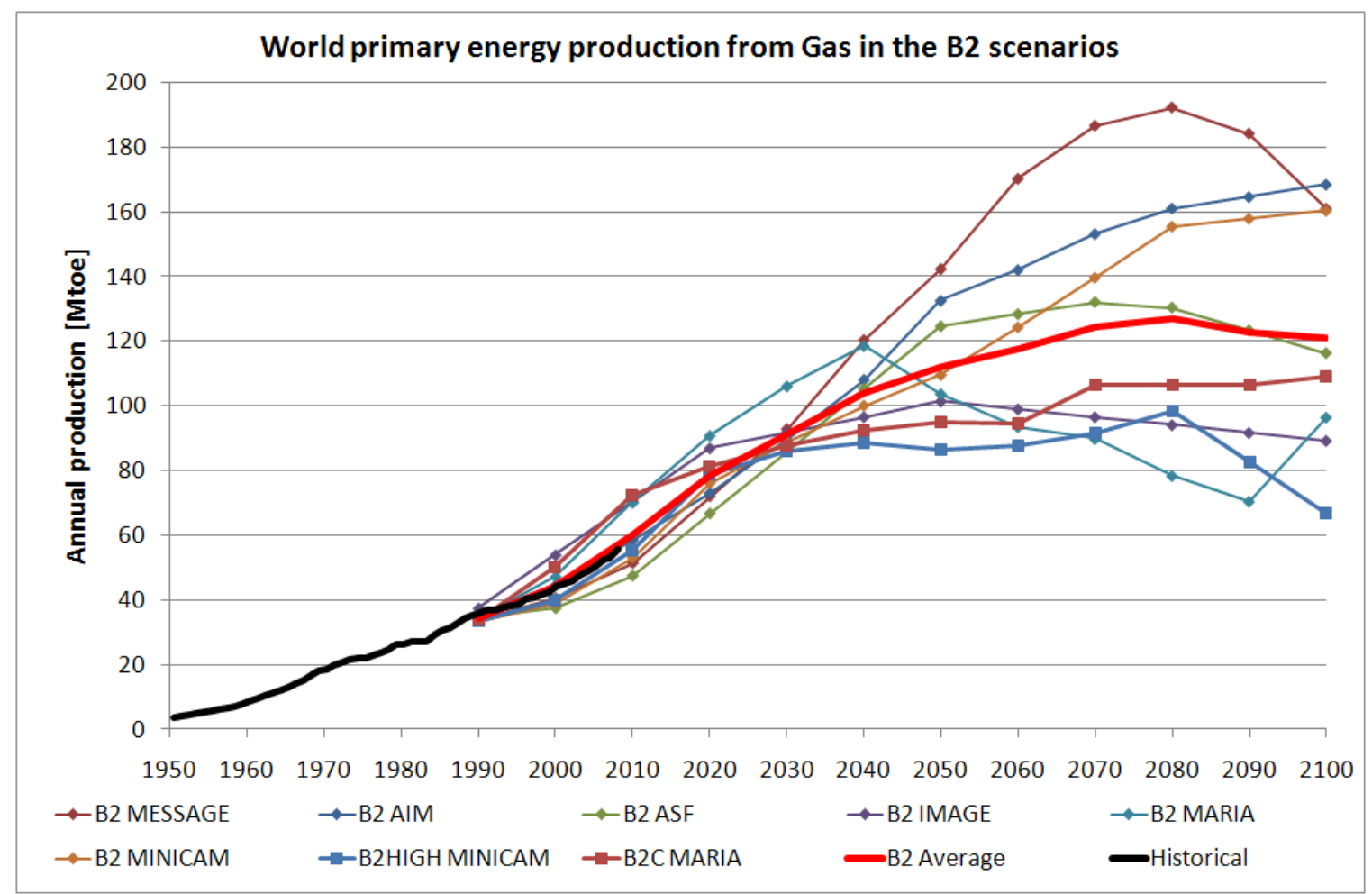

Figure 13: Projected gas production in the B2 scenario family.

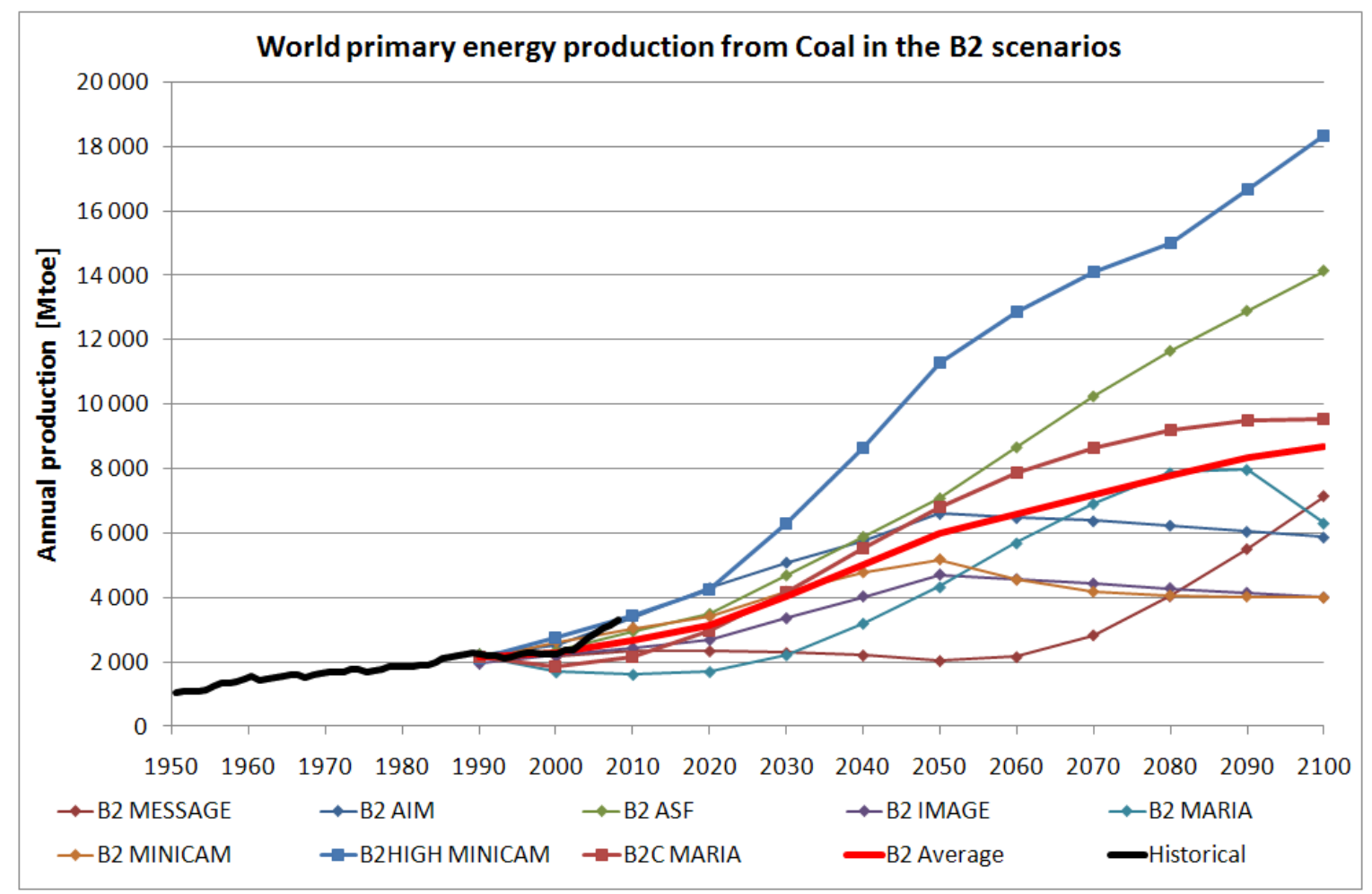

Figure 14: Projected coal production in the B2 scenario family. 


\section{Comments on the SRES production outlooks}

In retrospect, we know historical cumulative production figures for oil, gas and coal. Around $1100 \mathrm{~Gb}$ of oil have been produced since 1800 and present, along with nearly 600 Gboe of natural gas and 1100 Gboe of coal (Höök et al., 2009a). Generally, the most favourable formations have been exploited first while more challenging and/or undesirable formations have been left. In fact, various studies show that depletion can make up for technological progress in the industry (Livernois, 1988; Tilton, 2003; Rodriguez and Arias, 2008; Topp et al., 2008). In essence, the increased costs resulting from the need to mine less favourable formations, i.e. more complex geology, more remote areas, deeper or thinner coal seams, lower quality hydrocarbons and similar, have been matching the cost reductions done by increased mechanization and introduction of new technologies. However, SRES disregard such information based on little more than optimistic expectations on new technology.

The main message of Rogner (1997) directly shows misunderstanding of the actual problem as well as avoidance of the key question, namely future production. Society is dependent on fossil fuel flows and future production is about the size of those flows. The size of the tank, i.e. the resource base, is of secondary importance as it is the tap that governs the flow rate and future utilization of fossil fuels in the society. Vast unconventional hydrocarbon resources are useless for preventing the coming of a production peak if they cannot be developed fast enough. Vast reserve bases have little to do with the likelihood of significant future production, as production is dependent on many more factors than just geological availability.

A common main argument against a near-term peak is that vast amounts of nonconventional oil exist and that this are not considered in peak oil-models (Meng and Bentley, 2008). However, this is incorrect as many forecasts have included or studied flows on unconventional oil (Campbell and Sivertsson, 2003; Söderbergh et al, 2007; Robelius, 2007; Höök and Aleklett, 2009c). The important question for society is not the size of reserves. Rather it is the actual flow of oil or energy that can be obtained from the reserves.

The attenuation of the peak oil decline requires more than $10 \%$ of sustained growth of nonconventional oil production over at least the next two decades (de Castro et al., 2009). Such sustained growth rates have not been seen for any of the global energy systems in history (Höök et al, 2009a) and are not expected by either of the dominating forecasting agencies, i.e. the IEA or the EIA. Even the BGR (2008) states that: "after peak oil, the nonconventional oil production will rather modify the decline in oil supply than close the gap between demand and supply"

Furthermore, actual details on geographic distribution of reserves/resources and production is not discussed in any detail by SRES (2000) or the sources it relies on. The significant dependence on roughly 300 giant oil fields, which account for $60 \%$ of world oil production, and the challenge in replacing them with new production have been discussed by Robelius (2007) and Höök et al. (2009b). The decline in existing production has been determined to be around $6 \%$ and this is a commonly accepted figure derived by several analysts, both from "optimistic" and "pessimistic" standpoints regarding future production (Höök et al. 2009b and references therein).

The observed decline equals required new annual production additions of 3-7 $\mathrm{Mb} / \mathrm{d}$ and this puts some real numbers on what is required just to offset decrease in 
existing production. Even more additions are required for maintaining production growth and petroleum industry have pointed to the problems with sustaining growing output. Most notably is perhaps the statement that the world oil production never will reach above $89 \mathrm{Mb} / \mathrm{d}$ from super major oil company Total (Hoyos, 2008). The lack of detailed discussion on the future production in SRES is questionable, as details such as the giant fields have significant impact on actual production. The aggregated models and generalized assumptions strike us as problematic and should be brought out in the open. At this point, IPCC and SRES (2000) seem far more optimistic regarding future fossil fuel production than the industry itself.

The lack of details regarding coal-to-liquids (CTL) conversion ratios have been highlighted by Höök and Aleklett (2009c). CTL technology costs are assumed to be very low, typically below 30 dollars/barrel and even as little as 16 dollar/barrel in some cases (SRES, 2000). Such assumptions seem rather unsound compared to more recent and updated assessments, which ends up around 48-75 US\$/barrel (Vallentin, 2009). CTL is assumed to be a vital part of future fuel supply in several scenarios. For example, the world CTL production (32 Mb/d) by 2100 in B2 MESSAGE scenario is higher than the world oil production at the same time and more than the present world coal consumption would reasonable be consumed by synthetic fuel plants. Can such assumptions really be made with little more than vague arguments based on technical possibilities?

Milkov (2004) highlights how worldwide estimates of gas hydrates have decreased by many orders of magnitude, from $10^{18} \mathrm{~m}^{3}$ in $1970 \mathrm{~s}$ to $10^{15} \mathrm{~m}^{3}$ in $2000 \mathrm{~s}$, and attributes this to growing geological knowledge. In other words, many of the sources Rogner (1997) depends on are obsolete. An excellent review on facts and myths surrounding gas hydrates and their future as an energy source have been made by Beauchamp (2004). The apparent importance of gas hydrates and the major expectation that are put on them in SRES (2000) seem debatable and should be brought out for more discussion. The huge global estimates of hydrate methane are suspicious at best, and have nothing to do with the likelihood that hydrates will provide energy supply assurance for the future.

In summary, we can only encourage the IPCC to involve more resource experts and natural scientists in future emission scenarios. The current set, SRES (2000), is biased toward exaggerated resource availability and unrealistic expectations on future production outputs.

\section{Conclusions}

Perpetual economic growth is only an extrapolation from history, not a law of nature. Decline and the coming of a production peak are both phenomenological observations as well as results derived from physical models, such as decreasing flows due to lower reservoir pressure induced by depletion of the recoverable oil.

However, perpetual growth is often held as a pious belief and fundamental assumption for economists. Perpetual growth cannot be used as an underlying assumption for non-renewable energy sources, such as fossil fuels. Even former technological and economic optimists are now seeing the end of an era with exponential growth (Ayres, 2006). This is hardly surprising, given the underlying arithmetic properties of growth and how quickly unreasonable values are reached for resource production and consumption even for modest growth rates (Bartlett, 1993, 1999, 2004). 
SRES is riddled with future production projections that would put unreasonable expectation on just a few countries or regions. It is reasonable to expect that China, among the world's largest coal reserve and resource holder and producer, would increase their production by a factor of 8 over the next 90 years, as implied by the A1C-scenarios? Can methane hydrates be brought into production fast enough to offset declining conventional supply along with maintaining the overall production increase as implies in several scenarios? Many countries will have to rapidly increase their domestic production and consumption by absurdly large factors to fulfil the scenarios.

Both Smil (2000) and Bezdek and Wendling (2002) point out that long range energy forecasters have made numerous inaccurate projections, mostly in the form of overestimations. Additionally, many inaccurate forecasts were done in good faith with state-of-the-art models, competent researchers and good funding, showing the difficulty of long-range energy forecasting.

We argue that numerous SRES scenarios need to be revised, generally downward, regarding production expectations from fossil fuels. Several scenarios agree poorly with reality over the recent years and some can even be ruled out. SRES is underpinned by a paradigm of perpetual growth and technological optimism as well as old and outdated estimated regarding the availability of fossil energy. Just as its withdrawn preceding report from 1992 (Gray, 1998), the future energy production projections for fossil in SRES (2000) are exaggerated and so are the resulting emissions. What kind of repercussions this has on the future climate is an open question which needs to be assessed from several different angles.

\section{Acknowledgements}

The authors would like to thank Dr Herbert West for valuable inspiration, as well as Dave Rutledge for good and constructive discussions. Larry Hughes has our sincerest appreciation for proofreading.

\section{References}

Adelman M.A, Lynch, M.C., 1997. Fixed view of resource limits creates undue pessimism, Oil and Gas Journal, 95(14):56-60

Aleklett, K., Campbell, C., 2003. The Peak and Decline of World Oil and Gas Production, Minerals \& Energy Raw Materials Report, 18(1):5-20

Ayres, R.U., 2006. Turning point: The end of exponential growth? Technological Forecasting and Social Change, 73(9):1188-1203

Bartlett, A.A., 1993. Arithmetic of Growth: Methods of Calculation, Population and Environment, 14(4):359387

Bartlett, A.A., 1999. Arithmetic of Growth: Methods of Calculation II, Population and Environment, 20(3):215246

Bartlett, A.A., 2004. The Essential Exponential! For the Future of Our Planet, Center for Science, Mathematics and Computer Education, University of NebraskaLincoln, $302 \mathrm{p}$

Beauchamp, B., 2004. Natural gas hydrates: myths, facts and issues, Comptes Rendus Geoscience, 36(9):751 765
Bentley, R.W., Boyle, G., 2007. Global oil production: forecasts and methodologies, Environment and Planning B: Planning and Design, 35(4):609-626

Bentley, R.W., Mannan, S.A., Wheeler, S.J., 2007. Assessing the date of the global oil peak: The need to use $2 P$ reserves, Energy Policy, 35(12):6364-6382

Bezdek, R.H., Wendling, R.M., 2002. A Half Century of Long-Range Energy Forecasts: Errors Made, Lessons Learned, and Implications for Forecasting, Journal of Fusion Energy, 212(3-4):155-172

BGR, 1980-2008. Reserves, Resources and Availability of Energy Resources 2007 and previous reports, see also: http://www.bgr.bund.de/

BP, 2009. BP Statistical Review of World Energy 2009, see also: http://www.bp.com

Brecha, R.J., 2008. Emission scenarios in the face of fossilfuel peaking. Energy Policy, 36(9):3492-3504

Campbell, C.J., 1997. Better understanding urged for rapidly depleting reserves, Oil and Gas Journal, 95(14):51-54

Campbell, C., Laherrère, J., 1998. The end of cheap oil, Scientific American, March 1998

Campbell, C.J., Sivertsson, A., 2003. Updating the depletion model. Proceedings of the Second 
International Workshop on Oil Depletion, Paris, France, 26-27 May 2003. See also: http://www.peakoil.net/iwood2003/paper/CampbellPap er.doc

Castles I., Henderson D., 2003. The IPCC Emission Scenarios: An Economic-Statistical Critique, Energy \& Environment, 14(2-3):159-185

Collett, T.S, Kuuskraa, V.A., 1998. Hydrates contain vast store of world gas resources, Oil \& Gas Journal, 96(19):90-95

Collett, T.S., 2002. Energy resource potential of natural gas hydrates, AAPG Bulletin, 86(11):1971-1992

de Castro, C., Miguel, L.J., Mediavilla, M., 2009. The role of non conventional oil in the attenuation of peak oil, Energy Policy, 37(5):1825-1833

Energywatch Group, 2007. Coal: resources and future production, report from March 2007. See also: http://www.energywatchgroup.com/

Girod, B., Wiek, A., Mieg, H., Hulme, M., 2009. The evolution of the IPCC's emissions scenarios, Environmental Science \& Policy, 12(2):103-118

Green, K.C., Armstrong, J.S., Soon, W., 2009. Validity of climate change forecasting for public policy decision making, International Journal of Forecasting, 25(4):826-832

Greene, D.L., Hopson, J.L., Li, J., 2006. Have we run out of oil yet? Oil peaking analysis from an optimist's perspective, Energy Policy, 34(5):515-531

Gregory, K., Rogner, H.H., 1998. Energy resources and conversion technologies for the 21st century, Mitigation and Adaptation Strategies for Global Change, 3 (24):171-229

Gray, V., 1998. The IPCC future projections: are they plausible? Climate Research, 10(2):155-162

Hirsch, R.L., Bezdek, R., Wendling, R., 2005. Peaking of world oil production: impacts, mitigation and risk management, US Dept. Energy/National Energy Technology Lab, February 2005

Hjerpe, M, Linnér, B.O., 2008. Utopian and dystopian thought in climate change science and policy, Futures, Volume 41, Issue 4, May 2009, Pages 234-245

Hoyos, C., 2009. Total says oil output is near its peak, Financial Times, 16 February 2009, see also: http://www.ft.com/cms/s/0/1df0bc9c-fbc7-11dd-bcad000077b07658.html?nclick_check=1

Hubbert, M.K., 1956. Nuclear energy and the fossil fuels, Publication No.95, 40 pp., Shell Development Company, Houston, Texas.

Hubbert, M.K., 1982. Response to David Nissens remarks, see http://www.hubbertpeak.com/Hubbert/to nissen.htm

Höök, M., Aleklett, K., 2009a. Historical trends in American coal production and a possible future outlook, International Journal of Coal Geology, Volume 78, Issue 3, May 2009, Pages 201-216

Höök, M., Aleklett, K., 2009b. Trends in U.S. Recoverable Coal Supply Estimates and Future Production Outlooks, paper presented at International Pittsburgh Coal Conference 2009

Höök, M., Aleklett, K., 2009c. A review on coal to liquid fuels and its coal consumption, International Journal of Energy Research, article in press

Höök, M., Junchen, L., Feng, L., Aleklett, K., 2009a. Growth rates of global energy systems and future outlooks, research report GES PP-10:1,

Höök, M., Hirsch, R., Aleklett, K., 2009b. Giant oil field decline rates and their influence on world oil production, Energy Policy, 37(6):2262-2272

IEA, 2008. Key world energy statistics 2008, annually published statistics book. See also: http://www.iea.org/textbase/nppdf/free/2008/key stats 2008.pdf

IEA, 2008b. World Energy Outlook 2008, see also: http://www.worldenergyoutlook.com

IPCC, 1990. First Assessment Report, see also: http://www.ipcc.ch/ipccreports/assessments-reports.htm

IPCC, 1995. Second Assessment Report - Climate Change 1995. see also: http://www.ipcc.ch/ipccreports/assessments-reports.htm

IPCC, 2001. Third Assessment Report - Climate Change 2001, see also: http://www.ipcc.ch/ipccreports/assessments-reports.htm

IPCC, 2007. Fourth Assessment Report - Climate Change 2007, see also: http://www.ipcc.ch/ipccreports/assessments-reports.htm

Ivanhoe L.F., Leckie, G.G., 1993. Global oil, gas fields, sizes tallied, analyzed, Oil and Gas Journal, 91(7):87-91

Jakobsson, K., Söderbergh, B., Höök, M., Aleklett, K., 2009. How reasonable are oil production scenarios from public agencies? Energy Policy, 37(11):48094818

Jevons, W.S., 1856. The Coal Question: An Inquiry Concerning the Progress of the Nation, and the Probable Exhaustion of Our Coal-Mines. London: Macmillan and Co., 1866 (Second edition, revised). See also:

http://www.econlib.org/library/YPDBooks/Jevons/jvnC Q.html

Jones, R.N., 2001. An environmental risk assessment/management framework for climate change impact assessments, Natural Hazards, 23(2-3):197-230

Kharecha, P.A., Hansen, J.E., 2008. Implications of "peak oil" for atmospheric CO2 and climate, Global Biogeochemical Cycles, 22(3)

Laherrere, J., 1994. Published figures and political reserves, World Oil, January 1994, page 33

Laherrere, J., 1999. Data shows oceanic methane hydrate resource over-estimated, Offshore, 59(9):156-158

Laherrere, J., 2000. Oceanic hydrates: more questions than answers, Energy Exploration \& Exploitation, 18(4):349-383

Laherrere, J., 2001. Estimates of Oil Reserves, paper presented at the EMF/IEA/IEW meeting, International Institute for Applied Systems Analysis (IIASA), Laxenburg, Austria - June 19, 2001

Livernois, J.R., 1988. Estimates of marginal discovery costs for oil and gas, Canadian Journal of Economics, 21:379-393

Kontorovich, A.E., 2009. Estimate of global oil resource and the forecast for global oil production in the 21st century, Russian Geology and Geophysics, 50(4):237242

McKibbin W.J., Pearce, D., Stegman, A., 2007. Long term projections of carbon emissions, International Journal of Forecasting, 23(4):637-653

Meadows, D.H., Meadows, D.L., Randers, J., Behrens, W., 1972. The Limits to Growth, New York: Universe Books, 205 p

Meng, Q.A., Bentley, R.W., 2008. Global oil peaking: Responding to the case for 'abundant supplies of oil', Energy, 33(8):1179-1184

Milici, R.C., 2009. Coal-to-Liquids: Potential Impact on U.S. Coal Reserves, Natural Resources Research, 18(2):85-94

Milkov, A.V., 2004. Global estimates of hydrate-bound gas in marine sediments: how much is really out there? Earth-Science Reviews, 66(3-4):183-197

Mohr, S.H, Evans, G.M., 2009. Forecasting coal production until 2100, Fuel, 88(11):2059-2067 
Moritiary, P., Honnery, D., 2009. What energy levels can the Earth sustain? Energy Policy, 37(7):2469-2474

Nel, W.P., Cooper, C.J., 2009. Implications of fossil fuel constraints on economic growth and global warming, Energy Policy, 37(1):166-180

Robelius, F., 2007. Giant oil fields - the highway to oil: giant oil fields and their importance for future oil production, doctoral thesis from Uppsala University, see also: http://uu.divaportal.org/smash/record.jsf?pid=diva2: 169774

Rodríguez, X.A., Arias, C., 2008. The effects of resource depletion on coal mining productivity, Energy Economics, 30(2):397-408

Rogner, H.H., 1997. An assessment of world hydrocarbon resources, Annual Review of Energy and the Environment, 22:217-262

Ruppert, L., Kirschbaum, M., Warwick, P., Flores, R., Affolter, R., Hatch, J., 2002. The US Geological Survey's national coal resource assessment: the results, International Journal of Coal Geology, 50(1-4):247-274

Rutledge, D., 2007. Hubbert's Peak, the Coal Question, and Climate Change, presentation at the ASPO-USA World Oil Conference, 17-20 October 2007, Houston, Texas, see also: http://rutledge.caltech.edu/

Schenk, N.J., Lensink, S.M., 2007. Communicating uncertainty in the IPCC's greenhouse gas emissions scenarios, Climatic Change, 82(1-2):293-308

Sivertsson, A., 2004. Study of World Oil Resources with a comparison to the IPCC Emissions Scenarios, diploma thesis from Uppsala University 2004, see also: http://www.tsl.uu.se/uhdsg/Publications/Sivertsson The sis.pdf

Smil, V., 2000. Perils of Long-Range Energy Forecasting. Reflections on Looking Far Ahead, Technological Forecasting and Social Change, 65(3):251-264.

SRES, 2000. Special Report on Emissions Scenarios, report prepared by the Intergovernmental Panel on Climate Change (IPCC) for the Third Assessment Report. November 2000. See also: http://www.grida.no/publications/other/ipce_sr/?src=/cl imate/ipcc/emission/

Suslick, S.B, Machado, I.F., 2004. Non-renewable Resources, In: Natural resources policy and management, Encyclopedia of Life Support Systems (EOLSS), Developed under the Auspices of the UNESCO, Eolss Publishers, Oxford, UK, http://www.eolss.net

Söderbergh, B., Robelius, F., Aleklett, K., 2007. A crash programme scenario for the Canadian oil sands industry, Energy Policy, 35(3):1931-1947

Thomas, L., 2002. Coal geology, Chichester: John Wiley and Sons, $384 \mathrm{p}$.

Tilton, J.E., 2003. Assessing the Threat of Mineral Depletion, Minerals and Energy, 18:33-42

Tol, R.S.J., 2006. Exchange Rates and Climate Change: An Application of Fund, Climatic Change, 75(1-2):59-80

Topp, V., Soames, L., Parham, D., Bloch, H., 2008. Productivity in the Mining Industry: Measurement and Interpretation, Productivity Commission Staff Working Paper, see also: http://www.pc.gov.au/ data/assets/pdf file/0005/8491 1/mining-productivity.pdf

Turner, G.M., 2008. A comparison of The Limits to Growth with 30 years of reality, Global Environmental Change, 18(3):397-411

Vallentin, D., 2009. Policy drivers and barriers for coal-toliquids (CTL) technologies in the United States, Energy Policy 2008; 36(8):3198-3211

van Ruijven, B., Urban, F., Benders, R.M.J., Moll, H.C., van der Sluijs, J.P., de Vries, B., van Vuuren, D.P.,
2008. Modeling energy and development: an evaluation of models and concepts, World Development, 36(12):2801-2821

van Vuuren, D.P., O'Neill, B.C., 2006. The Consistency of IPCC's SRES Scenarios to 1990-2000 Trends and Recent Projections, Climatic Change, 75(1-2):9-46

Verhulst, P.F., 1838. Notice sur la loi que la population suit dans son accroissement, Correspondence Mathematique et Physique, 10:113-121

UK Industry Task Force on Peak Oil \& Energy Security, 2008. The Oil Crunch - securing the UK's energy future, report from 29 October 2008. See also: http://peakoil.solarcentury.com/wpcontent/uploads/2008/10/oil-report-final.pdf

Walsh, K.J.E., Betts, H., Church, J., Pittock, A.B., McInnes, K.L., Jackett, D.R., McDougall, T.J., 2004. Using Sea Level Rise Projections for Urban Planning in Australia, Journal of Coastal Research, 20(2): 586598

World Energy Council, 2007. Survey of Energy Resources 2007, see also: http://www.worldenergy.org 